1

.

28

31

\title{
Ground subsidence in Tucson, Arizona, monitored by time-series analysis using multi-sensor InSAR datasets from 1993 to 2011
}

7

8

9

0

1

22

4

25

6

27

29

30

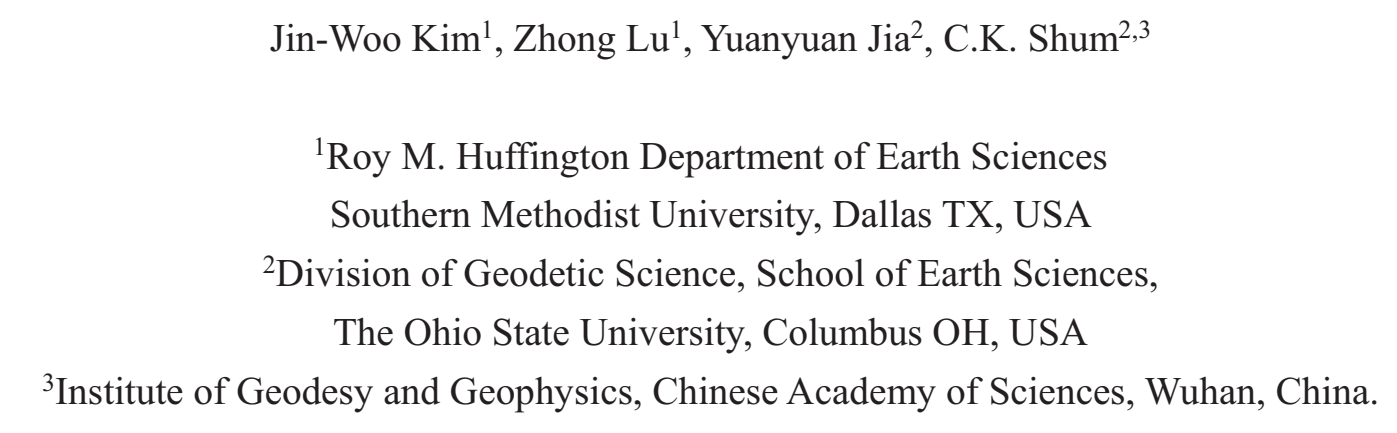 \\ Southern Methodist University, Dallas TX, USA




\section{Abstract}

38 The groundwater in Tucson, Arizona, is a major source for water supply to human

39 residential areas and agricultural use, and the groundwater extraction causes ground

40 deformation responding to aquifer-system compaction. Using multi-temporal C-band

41 and L-band SAR images from ERS/Envisat and ALOS PALSAR satellites, we mapped

42 the ground displacement in Tucson. The InSAR-derived ground displacement based on

43 small baseline subset technique (SBAS) is compared to compaction from

44 extensometers, land subsidence from GPS survey, and groundwater elevation at wells.

45 Tucson is characterized by slow and relatively small subsidence over areas with upper

46 stratigraphic till early 2000s when the groundwater had been extremely depleted and by

47 uplifts in areas where the water level has been recently recovered into the slight increase

48 of water table because of recharge into the aquifer. Our multi-sensor SBAS InSAR-

49 derived vertical displacements enabled to monitor the temporal variability in the spatial

50 extent and magnitude of the ground deformation, suggesting that recent ground

51 subsidence is slowing down and the ground motion in places is stable. Our results can

52 provide scientific basis for sound management of ground water pumping and recharge

53 over the study area. 
55 Keywords: InSAR, SBAS, groundwater extraction, Tucson, Aquifer-system compaction,

56 ground subsidence

57

58 1. Introduction

59 The groundwater is a major source for supplying drinking water to residents in

60 arid lands, irrigating plants for agriculture, and flowing into lakes or rivers. The rain

61 water, snowmelt, and inflow from upper watershed leads into the recharge of

62 groundwater, and the discharge is made by natural flow and human demands for

63 industrial, municipal, and agricultural purposes. Natural condition is balancing between

64 recharge and discharge, but the balance has been threatened by extreme consumption of

65 groundwater for developing arid areas of Phoenix and Nevada in the United States,

66 Libya, and India. The groundwater depletion caused the disappearance of a crucial

67 water resource as well as the aquifer-system compaction and ground subsidence. More

68 than 80 percent of the identified subsidence in the United States is caused by human

69 activities on subsurface water (Galloway et al., 2000). To conserve the groundwater and

70 circumvent more rapid consumption from the subsurface, the elaborate resource

71 management and intensive governmental efforts are required.

72 In Tucson, Arizona, the groundwater has been a critical resource for urban and 
73 rural communities, and the rapid urbanization and growing population has been heavily

74 dependent on groundwater because of the lack of surface water. The excessive

75 consumption of groundwater led to the decrease of water table as much as $14 \mathrm{~m}$

76 between 1989 and 2005, and the declined water level before 1989 was much bigger than

77 this number (Carruth et al., 2007). The groundwater pumping in excess of natural

78 recharge was the major cause of aquifer-system compaction and associated land

79 subsidence in Tucson area (Pool and Anderson, 2007). Since the Arizona's 1980

80 Groundwater Management Act, the temporal variations of groundwater table, soil

81 compaction, and land subsidence have been monitored by gauges in wells, borehole

82 extensometers, and annual GPS survey at multiple stations (Carruth et al., 2007; Pool

83 and Anderson, 2007). These methods provide a good precision of measurement on

84 subsurface condition, but each has limitation in detecting land-surface motion over large

85 areas associated with groundwater depletion. For example, the water level at wells is not

86 highly correlated with surface deformation in many cases, and the extensometers cannot

87 measure the compaction occurring below the anchor depth of the devices. The annual

88 GPS survey in sparse stations, which is labor-intensive, does not measure the surface

89 displacement with high accuracy like continuous GPS. In contrast, the spatially detailed

90 images of ground displacements generated from SAR interferometry (InSAR) can help 
91 to monitor the ground subsidence in Tucson.

The InSAR is an invaluable tool for measuring displacements over a large area

93 with high accuracy of sub-centimeter and high spatial resolution of $30 \mathrm{~m}$ after spatial

94 averaging and geocoding. The InSAR processing for detecting displacements after

95 removing topographic and orbital error phases and reducing as much atmospheric

96 artifact as possible is particularly called the differential InSAR (DInSAR). The DInSAR

97 has been used for detecting horizontal and vertical displacements caused by catastrophic

98 natural disasters of earthquakes and volcanoes, anthropologic deformation caused by

99 mining and oil/gas extraction, and deformation induced by melting of permafrost

100 (Hanssen, 2001; Tong et al., 2010; Lu et al., 2007; Samsonov et al., 2011).

101 In particular, the DInSAR was used for measuring the surface displacements

102 related to aquifer system compaction and uplift accompanying groundwater discharge

103 and recharge (Lu and Danskin, 2001; Galloway and Hoffman, 2007). Several

104 researchers (Galloway et al., 1998; Hoffmann et al., 2003) mapped aquifer-system

105 compaction and subsidence in the Antelope Valley, California, by integrating DInSAR,

106 GPS, and extensometers, and successfully estimated the groundwater flow, storage

107 change, and compaction over large areas. The water decline and clay thickness map in

108 Las Vegas Valley was analyzed with subsidence map based on DInSAR, GPS, and 
109 leveling (Amelung et al., 1999; Bell et al., 2002) and inelastic and elastic deformation

110 caused by seasonal variation was detected by DInSAR time-series analysis. Schmidt

111 and Burgmann (Schmidt and Burgmann, 2003) used the DInSAR for measuring surface

112 subsidence by groundwater extraction in Santa Clara Valley, California and found the

113 Silver Creek Fault to disrupt the groundwater flow and cause steep displacement

114 gradients. The recent advance in the DInSAR technology can improve the accuracy of

115 surface deformation measurements. The small baseline subset (SBAS) algorithm

116 exploiting multi differential interferograms of small baselines could be used to enhance

117 the understanding of the underlying deformation process in the groundwater-withdrawn

118 region with dense temporal interval (Berardino et al., 2002). The advantage of SBAS

119 technique is that it could minimize the atmospheric phase in InSAR pairs, capture the

120 pattern of deformation in time and space, and estimate non-linear time series of

121 deformation during a long time span by analyzing DInSAR pairs with short

122 perpendicular baselines (Berardino et al. 2002; Lanari et al., 2004; Samsonov et al., 123 2011).

124 In this paper, the SBAS InSAR technology was applied for detecting ground

125 subsidence in Tucson, caused by groundwater depletion. Using sufficient SAR data

126 archive from early 1990 s to 2011 , the spatial extent and magnitude of surface 
127 deformation in Tucson has been estimated. Our study utilized ERS-1/2, ENVISAT, and

128 ALOS PALSAR, and the results of multi-sensor SBAS InSAR processing are analyzed

129 in spatio-temporal scale with supplementary data from gauges, extensometers, and GPS

130 survey.

131

132 2. Methodology

133 Standard DInSAR processing with small perpendicular baselines is required

134 before performing SBAS InSAR processing. The $N$ interferograms are generated from

135 MSAR images, which are coregistered on a common master image, by multiplying

136 master complex image with a conjugate of slave complex SAR data. To avoid spatial

137 decorrelation, a small orbital separation should be selected for further time-series

138 analysis. Moreover, the threshold of temporal baselines based on radar frequency and

139 coherence should be considered to prevent temporal decorrelation. The interferometric

140 phase of each interferogram is composed of a phase component caused by deformation,

141 topography, orbital error, atmosphere, and random noise term, respectively. The phase

142 components but deformation are reduced by using digital elevation model (DEM), least-

143 square fitted $2^{\text {nd }}$ order polynomial, and noise-suppressing filters. Because topography

144 provided by DEM sources has relative error terms and atmospheric phase is not easy to 
145 be removed from a single InSAR pair, the deformation phase cannot be reliably

146 obtained. If there is no phase unwrapping error, the observed interferometric phase $\phi_{i f g s}^{k}$

147 of $k^{\text {th }}$ differential interferogram consists of deformation $\phi_{\text {def }}^{k}$, topographic $\phi_{\text {topo }}^{k}$,

148 atmospheric $\phi_{a t m}^{k}$, and noise $\phi_{\text {noise }}^{k}$,

$$
\phi_{i f g s}^{k}=\phi_{d e f}^{k}+\phi_{t o p o}^{k}+\phi_{a t m}^{k}+\phi_{\text {noise }}^{k}
$$

150 In equation (1), both topographic phase and atmospheric phase terms are related

151 to errors and residuals in DInSAR processing. The residual topographic phase term is

152 estimated as (Berardino et al., 2002, Samsonov, 2010),

153

$$
\phi_{t o p o}^{k}=\frac{B_{\perp} \cdot \square z}{R \cdot \sin \theta}
$$

154 where $R$ is the line-of-sight distance between satellites and targets, $\theta$ is incidence

155 angles, $B_{\perp}$ is perpendicular baselines, and $\sqcup z$ is topographic error term. The

156 atmospheric phase can be classified into turbulent mixing and vertical stratification

157 contributions (Hanssen, 2001). The turbulent contributions are considered as a random

158 phase both in space and time while the vertical stratification contribution is correlated

159 with elevation (Delacourt et al., 1998; Beauducel et al., 2000; Chaabane et al., 2007;

160 López-Quiroz et al., 2009). Removing the effect of vertical stratification is a relatively

161 easy step by using a linear correlation between interferometric phase from each

162 interferogram and elevation from DEM, but the turbulent contribution, assumed as 
163 random, can be reduced by computing a least square solution from many interferograms

164 acquired under favorable conditions less influenced by spatial and temporal

165 decorrelation (Samsonov et al., 2013). The key feature of SBAS InSAR is that it can

166 reduce the random atmospheric phase from many InSAR pairs as well as estimating

167 topographic error terms related to the perpendicular baseline. Additionally, ionospheric

168 effects can induce the azimuthal image and Doppler Centroid distortion on low

169 frequency (L-band) radar system (Franz et al., 2006), but the artifacts due to ionosphere

170 were negligible in our used L-band SAR images.

171 To integrate the InSAR pairs from multi-sensor, additional process is needed to

172 correct the effect of the different wavelengths. As proposed by a previous study (Pepe et

173 al., 2005), ERS and ENVISAT SAR sensors have different center frequency $(5.30 \mathrm{GHz}$

174 for ERS-1/2 and 5.33 GHz for ENVISAT ASAR) and it is difficult to generate

175 interferogram from ERS/ENVISAR pairs. Instead, the ENVISAT InSAR pairs can be

176 integrated into SBAS algorithm, by multiplying the correction term $\left(\lambda_{\text {ENVISAT }} / \lambda_{\text {ERS }}\right.$,

$177 \lambda_{E R S}=5.656 \mathrm{~cm}$ and $\left.\lambda_{E N V I S A T}=5.624 \mathrm{~cm}\right)$ with unwrapped interferometric phases. If the

178 track of ENVISAT and ERS is identical, the incidence angle of ERS and ENVISAT is

179 similar in most cases (Table 1).

180 The fundamental equation for SBAS can be expressed as the following form, 
where $B$ matrix has dimensions of $N$ by $M-1$ ( $N$ and $M$ are the numbers of

adjacent acquisitions to be calculated. The $v$ vector is unknown as,

$$
v^{T}=\left(\begin{array}{lllll}
v_{1}=\frac{\phi_{1}^{i n c}}{t_{2}-t_{1}} & \cdots & v_{k}=\frac{\phi_{k}^{i n c}}{t_{k+1}-t_{k}} & \cdots & v_{M-1}=\frac{\phi_{M-1}^{i n c}}{t_{M}-t_{M-1}}
\end{array}\right)
$$

188 (acquisition date of $k+1^{\text {th }}$ SAR data ). In $B$ matrix, if a $k^{\text {th }}$ interferogram spans the time

189 represented by the column $n$, then the $b_{n}^{k}$ term is equal to the time interval between the consequent images, otherwise zero (Berardino et al., 2002; Samsonov, 2010). In order to correct the topographic error, a perpendicular baseline of each interferogram should be attached to the right side of the $B$ matrix. Additionally, in low coherence areas, which do not have consistent scattering between acquisition dates, the interferometric phase is set to zero, and the phase value should be excluded for SBAS analysis. $t_{1}, \square, t_{4}$ five interferograms are generated from intervals $t_{2}-t_{1}, t_{3}-t_{1}, t_{3}-t_{2}, t_{4}-t_{2}$, $t_{4}-t_{3}$, and the interferometric phase at a pixel of a particular pair (here, InSAR pair 
199 non-deformation, the SBAS equation can be formulated as $\left(\Phi_{i f g s=} T B v=\tilde{B} v(5)\right)$,

$$
\left(\begin{array}{c}
\phi_{i f g s}^{1-2} \\
\phi_{i f g s}^{1-3} \\
\phi_{i f g s}^{2-3} \\
\phi_{i f g s}^{2-4} \\
\phi_{i f g s}^{3-4}
\end{array}\right)=\left(\begin{array}{lllll}
1 & 0 & 0 & 0 & 0 \\
0 & 1 & 0 & 0 & 0 \\
0 & 0 & 0 & 0 & 0 \\
0 & 0 & 0 & 1 & 0 \\
0 & 0 & 0 & 0 & 1
\end{array}\right)\left(\begin{array}{cccc}
t_{2}-t_{1} & 0 & 0 & B_{\perp}^{1-2} \\
t_{2}-t_{1} & t_{3}-t_{2} & 0 & B_{\perp}^{1-3} \\
0 & t_{3}-t_{2} & 0 & B_{\perp}^{2-3} \\
0 & t_{3}-t_{2} & t_{4}-t_{3} & B_{\perp}^{2-4} \\
0 & 0 & t_{4}-t_{3} & B_{\perp}^{3-4}
\end{array}\right)\left(\begin{array}{c}
v_{1} \\
v_{2} \\
v_{3} \\
\square z \\
\hline R \cdot \sin \theta
\end{array}\right)
$$

is properly performed, $T$ matrix will be same as $I(N \times N)$ identity matrix. When interferometric phase of $k^{\text {th }}$ interferogram is set to zero due to low coherence, $k \times k$

204 diagonal term of $T$ matrix will be zero. Due to the introduction of $T$ transformation

205 matrix, changing the size of design matrix $B$ is not needed for pixels of all

206 interferograms. Another problem of $\tilde{B}(N \times M)$ matrix is a rank deficiency, because

207 critical links of InSAR networks are often missing (i.e. unlinked InSAR pairs in Fig. 3)

208 due to low coherence of many pairs. In addition, the images might be divided to

209 separate networks due to the baseline configuration. The combination of all available

210 interferograms is based on a minimum norm criterion of the velocity deformation

211 (Berardino et al., 2002). The SVD (Singular Value Decomposition) inversion of $\tilde{B}$

212 matrix enables to solve equation (5) and obtain the unknown $v$ vector, but the

213 incremental phase delay of $v$ vector is set to zero by SVD, which biases the subsidence

214 temporal behavior and subsidence rate (López-Quiroz et al., 2009). The solution for the 
215 problem is using Tikhonov regularization (Tikhonov and Arsenin, 1977) or low-pass

216 filtering in the time domain (Samsonov and d'Oreye, 2012). Another solution is

217 considering the quadratic behavior of the incremental phase delay and adding constrains

218 to design matrix $\tilde{B}$. The solution supposes that deformation increases or decreases with

219 second order polynomials in time. Additionally, applying Gaussian filter in time to

220 estimated incremental phase smoothes deformation with avoiding the effect of rank-

221 deficiency and residual atmospheric error. We added the following constrain to the

222 inversion as proposed by previous study (López-Quiroz et al., 2009),

223

$$
\sum_{k=1}^{m} \phi_{k}^{i n c}=a\left(t_{m}-t_{1}\right)+b\left(t_{m}-t_{1}\right)^{2}+c
$$

224

where $a, b, c$ are constants describing the quadratic behavior of incremental phase terms

225 of $v$ vector at time of $m$. After this constraint is added to equation (5), the matrix system

226 becomes $\Phi_{i f g s}^{c}=B^{c} v^{c}$

227

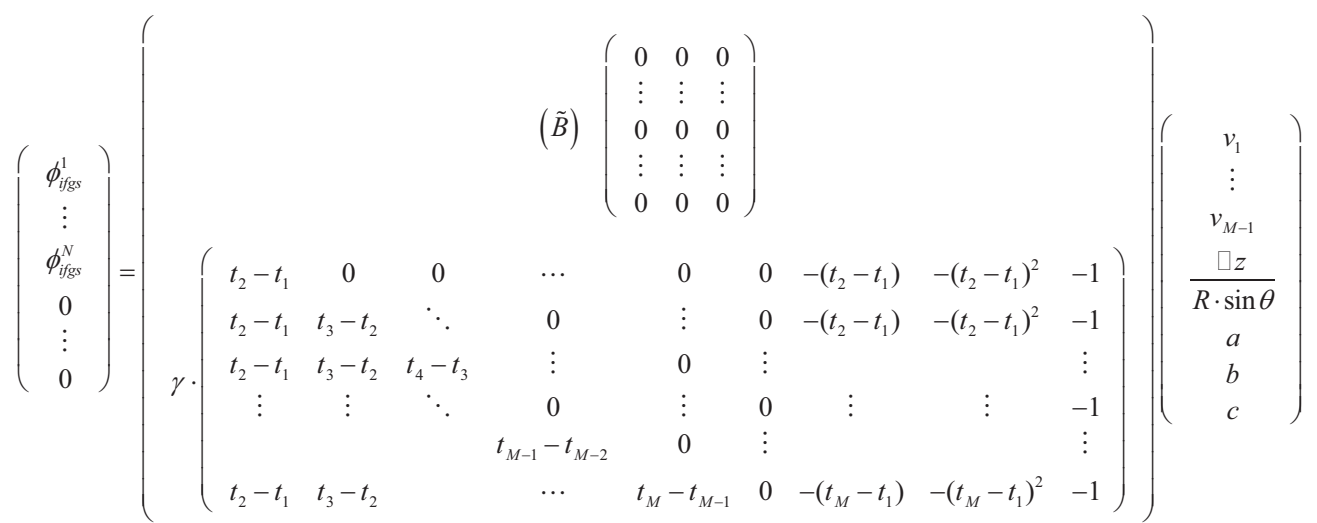

228 where the weight $\gamma$ is a scaling factor for the additional matrix of $B^{c}$

$229((N+M-1) \times(M+3))$, and the factor should be small enough so as not to affect the 
230 inversion of the major design matrix $\tilde{B}$. The inversion of $B_{c}^{T} B_{c}$ calculates the

231 incremental phase delay included in $v$ vector and its integration results in the cumulative

232 deformation phase at particular time.

233

234 3. Study area and data processing

2353.1 Characteristics of study region

236 Our study region is Tucson city in Arizona of southwest USA (Fig. 1). The

237 city's elevation ranges from 600 to $1300 \mathrm{~m}$, and most residential areas in downtown are

238 located between $800 \mathrm{~m}$ and $900 \mathrm{~m}$ at a relatively flat area contrary to mountains in the

239 west (Tucson mountains) and north (Santa Catalina mountains). The Santa Cruz River,

240 which flew along the west side of the Tucson, was a perennial river, but now a dry river

241 bed for most of the year except flooding by seasonal rains. Since the Santa Cruz River

242 became dry and the surface water had been gradually vanished, the city has been

243 dependent on the pumping of groundwater for residential use and agricultural irrigation.

244 Consequently, the water level measured in wells has been dramatically dropped as much

245 as $30 \mathrm{~m}$ since 1900s. The land subsidence and earth fissure occurred in Tucson and

246 southern Arizona and damaged the roads and civilian properties, but the phenomenon is

247 depending on the geological condition. The aquifer-compaction and land subsidence are 
248 associated with many parameters including soil composition, clay thickness, and soil

249 consolidation. The groundwater withdrawal in dry lands does not necessarily mean

250 ground subsidence, because regions with over-consolidated and incompressible soil, or

251 relatively thin aggregate clay thickness are less sensitive to the variation of water table

252 in aquifer. Furthermore, in areas with thick aquitards, the subsidence is often delayed

253 after water table is decreased (Galloway and Hoffmann, 2007). The geological

254 composition in Tucson can be grouped into three stratigraphic units (lower, middle, and

255 upper) and stream-channel alluvium (Fig. 2). The lower stratigraphic unit consists of

256 conglomerate, sandstone, mudstone, and gypsiferous mudstone. The middle

257 stratigraphic unit consists of clayey silt, mudstone, and gravel conglomerate. The upper

258 stratigraphic unit consists of gravel, clayey silt, and thin surficial alluvial deposits

259 (Carruth et al., 2007). Among those stratigraphic units, the upper stratigraphic unit is

260 more subject to land subsidence by groundwater extraction and, therefore, the Tucson

261 regions with upper stratigraphic unit have been more exposed to land subsidence. To

262 recover the groundwater storage and stop water level declines during the last several

263 decades, the Central Arizona Project pumped significant artificial recharge into the

264 aquifer. As a result, the recent groundwater withdrawal has been decreased, and the

265 water level in many wells indicates the increase of water table (Pool, 2005; Carruth et 
al., 2007).

267

\subsection{SBAS data processing}

269

For this study, 17 ERS-1/2, 24 ENVISAT ASAR, and 8 ALOS PALSAR images

270

(listed in Table. 1), covering the Tucson metropolitan area (Fig. 1), were utilized. ERS-

271

1/2 images including two ERS-1/2 tandem pairs of January, 11, 1996 January, 12,

2721996 and April, 25, $1996 \sim$ April, 26, 1996 were acquired from 1993 to 2002.

273 ENVISAT ASAR images are obtained between 2004 and 2010. Both ERS and

274 ENVISAT ASAR images are from the same descending track of 456 (Table 1),

275 meaning a similar radar geometry, but ERS/ENVISAT InSAR pair cannot be generated

276 due to the difference in center frequency. There is no temporal overlap of ERS and

277 ENVISAT SAR data, causing a data gap between 2002 and 2004. The ALOS PALSAR

278 images were acquired from ascending track, and the ALOS images covers a relatively

279 short time period from late 2009 to 2011 in contrast to C-band sensors.

280 For SBAS processing, ERS and ENVISAT InSAR pairs with perpendicular

281 baselines smaller than $500 \mathrm{~m}$ are generated. Furthermore, InSAR pairs with a good

282 coherence should be selected for reliable DInSAR processing including phase 
284 all 8 SAR images, because L-band InSAR pairs in Tucson are less influenced by

285 temporal and spatial decorrelation related to a large perpendicular baseline and a long

286 time interval (Sandwell et al., 2008).

287 1-arcsec national elevation dataset (NED) was used to remove topographic

288 contributions in DInSAR processing of ERS, ENVISAT and ALOS pairs. The precise

289 orbit information of ERS and ENVISAT is provided by Delft institute for earth-oriented

290 space research (DEOS). However, several InSAR pairs of ERS, ENVISAT, and ALOS

291 are deteriorated by orbital error fringes, which are then removed by $2^{\text {nd }}$ order

292 polynomial estimation in range and azimuth direction. From the figures (Fig. 4) of ERS,

293 ENVISAT, and ALOS differential interferograms, one can recognize that there are only

294 few phase variations in ALOS InSAR images (Fig. 4(e) and (f)), as the L-band sensor

295 (wavelength of $\sim 24 \mathrm{~cm}$ ) is less sensitive to slow-developing deformation by

296 groundwater extraction in Tucson (i.e. 2.2 (C-band) and 0.53 (L-band) radian change

297 according to $1 \mathrm{~cm}$ line-of-sight change) (Luo et al., 2014). Also, it is recognizable that

298 C-band interferograms of Fig. 4(a), (b), (c), and (d) show obvious signatures of ground

299 subsidence in downtown of Tucson, but other generated interferograms, not included in

300 Fig. 4, are deteriorated by atmospheric artifacts, particularly turbulent contributions that

301 do not correlate in time. In contrast, the effects of vertical stratification were negligible 
302 due to the flat terrain of our study area and their correction was not applied. For

303 example, Fig. 4(c) spans a short period, but many areas in the interferogram contain

304 atmospheric artifacts. Phase unwrapping after smoothing interferograms was applied by

305 minimum cost flow (MCF) algorithm.

306 One problem in integrating ERS and ENVISAT to SBAS algorithm in our

307 dataset is a data gap between the two groups of InSAR pairs (Fig. 3(a)), and the gap

308 causes a rank deficiency in SBAS processing owing to missing a critical link. To solve

309 the problem, the linear deformation rate is estimated from each ERS and ENVISAT

310 SBAS processing, and simulated temporary interferogram between the gap is generated

311 from averaging two linear deformation rates:

312

$$
\frac{1}{2}\left(\left(\frac{\sum \phi_{k}^{i n c}}{\sum t_{k}}\right)_{E R S}+\left(\frac{\sum \phi_{k}^{i n c}}{\sum t_{k}}\right)_{\text {ENVISAT }}\right) \cdot(\text { gapdays } / y r)
$$

313 The temporary interferogram is plotted as a dashed black line in Fig. 3(a). After SBAS

314 processing from ERS/ENVISAT and ALOS, all outputs are filtered by Gaussian filter in

315 time domain to suppress still-remaining atmospheric phase. Only 8 and 4 selected

316 deformation maps are shown in Fig. 5 and Fig. 6, respectively. The selected SBAS

317 InSAR-derived deformation maps are shown in Fig. 5, 6, and 7. forty time-series of

318 vertical displacements corresponding to each ERS and ENVISAT acquisition date are

319 generated (Fig. 5), and the number of C-band time-series is equal to $M$ (number of SLC 
320 data)-1. Seven time-series of vertical displacement corresponding to ALOS acquisition

321 date is then created (Fig. 6). A linear deformation rate (Fig. 7) is also estimated from C-

322 band and L-band SBAS processing. Note that the C-band deformation rate is calculated

323 from 1993 to 2010 , and the L-band deformation rate is from late 2009 to 2011 . Because

324 ALOS PALSAR data span relatively short period and their sensitivity to small

325 deformation was low compared to C-band dataset, we did not integrate the 2 results but

326 tried to assess them separately. Additionally, due to the same reason, we focused on

327 analyzing C-band results more than L-band time-series products.

328

329 4. Results and discussion

330 The water level in the subsurface has been monitored at wells densely located in

331 Tucson (operated by USGS Water Resources of Arizona). Because many wells were

332 installed before 1980 s, a long-term monitoring related to groundwater extraction has

333 been possible (i.e. Fig. 8; 10-year interval groundwater level). The groundwater level

334 from 1980s to 1990s (Fig. 8(a)) was dramatically dropped as much as $25 \mathrm{~m}$, and the

335 region of groundwater withdrawal was concentrated on a major residential area in

336 Tucson. The amount of groundwater extraction was gradually reduced during 1990s

337 (Fig. 8(b)), and the water level during 2000s (Fig. 8(c)) was recovered into a slight 
338 increase as a result of an artificial recharge into the aquifer-system. For 30 years

339 between 1980s and 2010s (Fig. 8(d)), most of water decline occurred during the first 10

340 years: the maximum water decline exceeded $25 \mathrm{~m}$, and most parts except the southern

341 area had water level decrease of approximately $12 \mathrm{~m}$.

342 The annual GPS survey campaign was conducted in multiple sites (red crosses

343 in Fig. 9(a)), and the extensometers (blue crosses) measured the compaction of aquifer-

344 system. The GPS-survey technique primarily estimated the vertical deformation from

345 measured ellipsoid heights, and the increased compaction measured by extensometers

346 implies downward land surface motion between land surface and the depth at which the

347 bottom of the extensometer is anchored (Carruth et al., 2007). The extensometer data

348 was acquired from USGS monitoring sites, and the annual GPS survey data is from

349 previous USGS report (Pool et al., 2007; Carruth et al., 2007). The green arrows (Fig.

3509 (b)) describe the compaction at the extensometer monitoring sites, and the length of

351 arrows describes the amount of compaction from October, 2005 to September, 2012.

352 Although there is a small number of extensometers, the region affected by large

353 groundwater extraction indicates large compaction possibly leading to ground

354 subsidence. The vertical deformation measured from annual GPS survey varies among

355 station locations, and the maximum subsidence between 1998 and 2005 reached 9.14 
356

357

358

359

360

361

362

363

364

365

366

367

368

369

370

371

372 373 cm (Fig. 9(b)).

From the results of ERS/ENVISAT SBAS processing (Fig. 5), a noticeable land

subsidence occurred in the center of Tucson city, around Davis Monthan Air Force

Base, and near the Tucson international airport. The deformation maps show the

cumulative land surface motion with respect to the acquisition date of the first SAR

image (June, 22, 1993). The vertical deformation in the center of Tucson city is about 14

$\sim 20 \mathrm{~cm}$ during 17-year period from 1993 to 2010, and the maximum subsidence of 24

cm occurred in the northern area of Tucson international airport. ALOS SBAS InSAR

processing (Fig. 6) has allowed us to obtain time-series of vertical deformation from the

first ALOS acquisition date (October, 17, 2009). The pattern of accumulated subsidence

from ALOS InSAR pairs is different from that of ERS/ENVISAR processing due to the

difference in the time-span and sensitivity to small subsidence. The linear deformation

rates are calculated from the SBAS results derived from the 2 datasets separately,

ERS/ENVISAT (Fig. 7(a)) indicate the maximum subsidence rate of $1.6 \mathrm{~cm} /$ year during

17 years, and ALOS SBAS processed results (Fig. 7(b)) delineate slowed maximum

subsidence rate of $0.6 \mathrm{~cm} /$ year between 2009 and 2011 (Note that The PALSAR

products in Fig. 6 and Fig. 7 are noisier than the ERS/ENVISAT results due to narrower

color range). 
375 SBAS processing are compared (Fig. 10), the ERS/ENVISAT and ALOS results of land

376 subsidence from 2006 to 2011 have general agreement at stations of WR53 and X419,

377 though both show difference between estimated deformation and compaction at

378 XAVIER and 23CBA. When we focus on the ERS/ENVISAT SBAS InSAR-derived

379 deformation (Fig. 10) in time-series, the subsidence in WR53 is about $0.8 \mathrm{~cm}$ with the

380 compaction of $0.5 \mathrm{~cm}$, and the vertical surface motion and compaction has a similar

381 amount. Based on only the extensometer measurements, it is hard to determine the

382 accuracy of SBAS InSAR processing (RMSE (Root Mean Square Error) $0.37 \pm 0.11$

$383 \mathrm{~cm})$. When considering the characteristics of the extensometers that cannot measure the

384 subsurface change below the bottom of the device, the comparison is within a category

385 of general agreement. The vertical displacements from ERS/ENVISAT and ALOS

386 SBAS InSAR processing and ellipsoid height change since 1998 (Pool et al., 2007) are

387 compared (Fig. 11). The accuracy of vertical measurement using GPS technology (error

388 bars in Fig. 11) is assumed to be $2.032 \mathrm{~cm}$ (Carruth et al., 2007). In most monitoring

389 stations, the results from GPS survey and SBAS InSAR show a similar pattern over

390 time, and the SBAS-derived deformations are within the uncertainties of GPS

391 measurements. Also, though ALOS pairs span only a short time period, the results from 
392 both ERS/ENVISAT and ALOS SBAS InSAR processing are in a good agreement. In

393 sites of B7A, WR56A, WR142, X419, and C45, both of GPS and SBAS InSAR-derived

394 deformation describes the ground subsidence due to the groundwater extraction.

395 However, in some places of MAGNETIC, WR53, and WR52, the ground was in uplift

396 and it could be attributed to rebounding of ground surface after groundwater recovery.

397 The temporal groundwater elevation measured at wells was also compared with

398 ERS/ENVISAT SBAS-processed vertical displacement (Fig. 12). The pattern of

399 groundwater elevation change was observed in most wells of Tucson. The groundwater

400 level was declining until 2003, and an artificial recharge and reduced consumption of

401 groundwater brought out the recent increase of water table. At station WR56A, the

402 ground subsidence was about $15 \mathrm{~cm}$ during observation period. The surface is still

403 subsiding after 2003 despite less rapidity. The continuous subsidence implies that the

404 subsidence could be affected by delayed compaction and inelastic behavior, while the

405 deformation is not recovered but permanent. In WR52, the land surface with increased

406 groundwater level is in uplift. It indicates that the displacement in the location is elastic,

407 while the increase of groundwater caused a recovery of subsurface.

408 The contour deformation map (Fig 13(a))) delineates several major subsidized

409 regions affected by groundwater extraction. A, B, and D regions are near the center of 
410 Tucson city, $\mathrm{C}$ is close to Davis Monthan Air Force Base, and E region is around the

411 northern part in Tucson International Airport. A and B regions have the subsidence of

412 about $14 \mathrm{~cm}$, and $\mathrm{C}$ and $\mathrm{D}$ areas are affected by $4 \mathrm{~cm}$ subsidence. E regions have the

413 maximum subsidence exceeding $20 \mathrm{~cm}$ during 17 -year span. When comparing the

414 contours of water level changes and linear deformation map (Fig. 7), and the subsidence

415 map (Fig. 14(a)), A and B regions are close to the areas of maximum water level

416 changes (up to $24 \mathrm{~m}$ ) since $1980 \mathrm{~s}$. C and D areas are overlapped with a region of

417 relatively small water level change (up to $10 \mathrm{~m}$ ). Because the change of groundwater

418 and surface motion is correlated, the result explains that the groundwater level change

419 caused the ground deformation in A, B, C, and D. On the other hand, other areas with

420 large water level change do not have a significant subsidence. The reasonable

421 assumption is that clay thickness is not sufficient for sensitive response to the change of

422 aquifer-system in the subsurface, or a soil layer is over-consolidated and incompressible

423 and the surface is very stabilized. E region with maximum subsidence is another

424 exception, because the groundwater level change is not highly correlated with

425 subsidence. The E region in Fig. 8(d) and 9(b) is in the mix of increase and decrease of

426 groundwater level, and the change of aquifer-system may not be a major cause of large

427 subsidence. Possibly, the human construction of roads, buildings, and airport can cause 
428 a large vertical deformation in E region, but, currently, it is not clear which factors

429 mostly affected the vertical deformation in E area.

430 One of great advantages of SBAS InSAR processing is that it could estimate

431 vertical deformation between two particular acquisition dates. The difference of

432 cumulative deformations of two particular dates can delineate temporal evolution of

433 subsidized areas in Tucson. Images in Fig. 13(b) (g) are generated from the difference

434 of deformation maps (Fig. 5) with about three-year interval, estimated from

435 ERS/ENVISAT SBAS InSAR processing. Red-colored regions in Fig. 13(b) (g) mean

436 ground subsidence, and dark red color is approximated as maximum subsidence.

437 Between 1996 and 1999, B and E region shows maximum subsidence exceeding 1.6

$438 \mathrm{~cm}$. During the span of 1999 and 2002, the maximum subsidence (dark red) of B and E

439 embraces the largest area in Tucson. Between 2004 and 2007 (Fig. 13(f)), the

440 subsidence rate of $\mathrm{A}$ and $\mathrm{B}$ is slowed down, but the $\mathrm{C}$ region has enlarged subsidence

441 area since 1999. The recent observation (Fig. 13(g)) indicates a slowing subsidence in

442 most regions of Tucson. The subsidence in A region is almost disappeared, and B region

443 shows only a small subsidence less than $1 \mathrm{~cm}$. The $\mathrm{C}$ region near Davis Monthan Air

444 Force Base shows still growing subsidized region from 1999 to 2010. The subsidence

445 area in E region between 2007 and 2010 is much smaller than the areas during other 
446 periods. Due to the similar time span, the Fig. 13(g) is well fitted to the result from

447 ALOS SBAS InSAR processing in Fig. 7(b), characterizing a major subsidence in B, C,

448 and E region. The profile along the lines of a-a', b-b', c-c', and d-d' in Fig. 13(c)

449 characterizes the features of slowing-down subsidence in Tucson (Fig. 14). The B and E

450 region shows the most prominent subsidence $(\sim 5 \mathrm{~cm})$ of 3-year interval from 1993 to

451 2010. In most regions, the subsidence between 1996 and 1999 is most significant and

452 the displacement from 2007 to 2010 is less than that from other 3-year periods.

453 However, the subsidence of C region was recently developed between 2007 and 2010 in

454 contrary to other regions. The images in Fig. 14 attest that the subsidence in most areas

455 is gradually slowing down due to the recharge of groundwater.

456

457 5. Conclusion

458 Our multi-sensor SBAS InSAR processing delineated a long-term development

459 of the vertical deformation from 1993 to 2011, though ALOS InSAR pairs covered a

460 relatively short time period between late 2009 and 2011. Most analyses focused on

461 products from ERS/ENVISAT SBAS processing due to a longer time-span and high

462 sensitivity to small and slow-developing subsidence. Although there is no a "real"

463 ground-truth reference in our interest area, the compaction from extensometer the 
464 ellipsoid height changes measured by the annual GPS survey show a similar pattern

465 with land subsidence estimated from SBAS processing in spite of differences in certain

466 stations. The 3-year interval maps of vertical deformation reveal the characteristics of

467 subsidence, which had occurred in Tucson. The subsidence during mid- and late-1990s

468 was significant around the large groundwater-withdrawal areas, but our results imply

469 that the recent subsidence in most areas of Tucson is slowing down and is about to

470 cease, based on the estimation between 2007 and 2010. The halting subsidence is

471 attributed to an intense effort to conserve groundwater, because Tucson is recharging

472 groundwater supplies by running part of its share of Central Arizona Project (CAP)

473 water into various open portions of local rivers to seep into their aquifer (Pool et al.,

474 2007). However, the human activities and still-progressing groundwater extraction can

475 be critical for the turn-around of current ceasing subsidence and future development of

476 deformation.

477 Our study has demonstrated that the SBAS InSAR processing is valuable for

478 estimating slow subsidence caused by spatio-temporal responses of aquifer system.

479 However, in this study, we assumed that groundwater withdrawal is the most dominant

480 factor in the subsidence of Tucson. Moreover, the human activities (i.e. constructing

481 buildings and airports) except groundwater use and other natural factors were not 
482 elaborately considered, but the future study should focus on unraveling more

483 parameters, which are related with ground motions. Additionally, the future dense

484 temporal and high-resolution SAR observations from Sentinel-1, TerraSAR-X, and

485 ALOS-2 PALSAR-2 will help to obtain more precise measurements and find more

486 robust relationship among ground deformation in Tucson, groundwater extraction, and

487 other parameters.

488

489 Acknowledgements

490 This research was supported by grants from the Shuler-Foscue Endowment at Southern

491 Methodist University and NASA's Earth Surface \& Interior Program (NNX14AD95G),

492 US Geological Survey (No. G12AC20468), NASA's NESSF Fellowship program

493 (NNX10AN54H) and Geodetic Imagery Program (No. NNX12AQ07G), and the

494 Chinese Academy of Sciences/SAFEA International Partnership Program for Creative

495 Research Teams (KZZD-EW-TZ-05). The InSAR results were generated by GAMMA

496 software, and most figures were created by GMT (Generic Mapping Tools).

497 


\section{References:}

Amelung, F., Galloway, D. L., Bell, J. W., Zebker, H., 1999. Sensing the ups and downs of Las Vegas: InSAR reveals structural control of land subsidence and aquifersystem deformation. Geology 27 (6), 483-486.

Bell, J. W., Amelung, F., Ramelli, A. R., Blewitt, G., 2002. Land subsidence in Las Vegas, Nevada, 1935-2000: New geodetic data show evolution, revised spatial patterns, and reduced rates. Environmental \& Engeering Geoscience 8 (3), 155174.

Berardino, P., Fornaro, G., Lanari, R., Sansosti, E., 2002. A new algorithm for surface deformation monitoring based on small baseline differential SAR interferograms. IEEE Transactions on Geoscience and Remote Sensing 40 (11), 2375-2383.

Carruth, R. L., Pool, D. R., Anderson, C. E., 2007. Land subsidence and aquifer-system compaction in the Tucson Active Management Area, south-central Arizona, 1987-2005. U.S. Geological Survey Scientific Investigations Report 2007-5190, $27 \mathrm{p}$.

Galloway, D. L., Hudnut, K. W., Ingebritsen, S. E., Phillips, S. P., Peltzer, G., Rogez F., Rosen, P. A.,1998. Detection of aquifer-system compaction and land subsidence using interferometric synthetic aperture radar, Antelope Valley, Mojave Desert, California. Water Resource Research 34, 2573-2585.

Galloway, D. L., Jones, D. R., Ingebritsen, S. E., 2000. Measuring land subsidence from space. U.S. Geological Fact Sheet 051-00, 4 p.

Galloway, D. L., Hoffmann, J., 2007. The application of satellite differential SAR interferometry-derived ground dis- placements in hydrogeology. Hydrogeology Journal 15 (1), doi: 10.1007/s10040-006-0121-5, 133-154.

Hanssen, R.F., 2001. Radar Interferometry: Data Interpretation and Error Analysis. Kluwer Academic Publishers.

Hoffmann, J. Zebker, H. A., 2003. Prospecting for horizontal surface displacements in Antelope Valley, California, using satellite radar interferometry. Journal of Geophysical Research 108 (F1), 6011. http://dx.doi.org/10.1029/2003JF000055.

Kim, J.-W., Lu, Z., Lee, H., Shum, C.K., Swarzenski, C. M., Doyle, T. W., Baek, S.-H., 2009. Integrated analysis of PALSAR/Radarsat-1 InSAR and ENVISAT altimeter data for mapping of absolute water level changes in Louisiana wetlands. Remote Sensing of Environment 113 (11), 2356-2365, ISSN 00344257, 10.1016/j.rse.2009.06.014.

Lanari, R., Mora, O., Manunta, M., Mallorquí, J. J., Berardino, P., Snasosti, E., 2004. A 
small-baseline approach for investigating deformations on full-resolution defferential SAR interferograms. IEEE Transactions on Geoscience and Remote Sensing 42 (7), 1377-1386.

López-Quiroz, P., Doin, M.-P., Tupin, F., Briole, P., Nicolas, J.-M., 2009. Time series analysis of Mexico City subsidence constrained by radar interferometry, Journal of Applied Geophysics 69, 1-15.

Lu, Z., Danskin, W., 2001. InSAR analysis of natural recharge to define structure of a ground-water basin, San Bernardino, California, Geophysical Research Letters 28, 2661-2664.

Lu, Z., 2007. InSAR imaging of volcanic deformation over cloud-prone areas Aleutian Islands. Photogrammatric Engineering \& Remote Sensing 73, 245-257.

Luo, Q., Perissin, D., Zhang, Y., Jia, Y. 2014. L- and X-band multi-temporal InSAR analysis of Tianjin subsidence. Remote Sensing 6, 7933-7951.

Meyer, F., Bamler, R., Jakowski, N., Fritz, T., 2006. The potential of low-frequency SAR systems for mapping ionospheric TEC distributions. IEEE Geoscience and Remote Sensing Letters 3 (4), 560-564.

Pepe, A., Sansosti, E., Berardino, P., Lanari, R., 2005. On the generation of ERS/ENVISAT DInSAR time-series via the SBAS technique. IEEE Geoscience and Remote Sensing Letters 2 (3), 265-169.

Pool, D. R., 2005. Variations in climate and ephemeral channel recharge in southeastern Arizona, United States. Water Resources Research 41, W11403, doi:10.1029/2004WR003255, 24 p.

Pool, D. R., Anderson, M. T., 2008. Ground-water storage change and land subsidence in Tucson Basin and Avra Valley, southeastern Arizona, 1998-

2002. U.S. Geological Survey Scientific Investigations Report 2007-5275, 34 p.

Samsonov, S., 2010. Topographic correction for ALOS PALSAR interferometry. IEEE Transactions on Geoscience and Remote Sensing 48 (7), 3020-3027.

Samsonov, S., Beavan, J., Gonzalez, P., Tiampo, K.J.F., 2011. Ground deformation in the Taupo Volcanic Zone, New Zealand observed by ALOS PALSAR interferometry. Geophysical Journal International 187 (1), 147-160.

Samsonov, S., d'Oreye, N., 2012. Multidimensional time series analysis of ground deformation from multiple InSAR data sets applied to Virunga Volcanic Province. Geophysical Journal International 191 (3), 1095-1108.

Samsonov, S., d'Oreye, N., Smets, B., 2013. Ground deformation associated with postmining activity at the French-German border revealed by novel InSAR time series method. International Journal of Applied Earth Observation and 
571 Sandwell, D. T., Myer, D., Mellors, R., Shimada, M., Brooks, B., Foster, J., 2008.

572 Accuracy and resolution of ALOS interferometry: Vector deformation maps of

573 the father's day intrusion at Kilauea. IEEE Transactions on Geoscience and

$574 \quad$ Remote Sensing 46 (11), 3524-3534.

575 Schmidt, D. A., Bürgmann, R., 2003. Time-dependent land uplift and subsidence in the

576 Santa Clara valley, California, from a large interferometric synthetic aperture

577 radar data set. Journal of Geophysical Research 108 (B9), 2416,

578 doi:10.1029/2002JB002267.

579 Tikhonov, A. N. Arsenin, V. Y., 1977. Solution of Ill-Posed Problems. V. H. Winston and $580 \quad$ Sons, Washington, DC.

581 Tong, X., Sandwell, D. T., Fialko, Y., 2010. Coseismic slip model of the 2008 Wenchuan earthquake derived from joint inversion of interferometric synthetic aperture radar, GPS, and field data, Journal of Geophysical Research 115, B04314, doi:10.1029/2009JB006625.

585 


\section{$586 \quad$ Figure Captions}

587 Figure 1. Tucson metropolitan area located in Pima county, Arizona.

588 Figure 2. Generalized geological map in Tucson metropolitan area. The geological

589 composition consists of upper, middle, and lower stratigraphic units. The area with

590 upper stratigraphic unit is subject to ground deformation.

591 Figure 3. Diagram of perpendicular and temporal baseline of InSAR pairs ((a) ERS and

592 ENVISAT InSAR pairs; red circles and lines are 29 ERS pairs, and blue circles and

593 lines are 134 ENVISAT pairs. And, dashed black line represents simulated temporary

594 InSAR pair to fill up data gap. (b) ALOS PALSAR InSAR pairs).

595 Figure 4. ERS-1/2 differential interferogram ((a) 1993.06.22 199601.11, (b)

596 1993.06.22 1997.03.07), ENVISAT differential interferogram ((c)

597 2004.01.30 2004.07.23, (d) 2004.01.30.2006.06.23), ALOS PALSAR differential

598 interferogram ((e) 2009.10.17 2011.03.07, (f) 2009.12.02 2011.03.07).

599 Figure 5. Time-series of (accumulated) vertical deformations from ERS/ENVISAT

600 SBAS InSAR processing of (a) 1993.11.09, (b) 1996.11.22, (c) 1999.10.08, (d)

601 2000.08.18, (e) 2004.12.10, (f) 2007.10.26, and (g) 2008.09.05, and (h) 2010.09.10.

602 Figure 6. Time-series of (accumulated) vertical deformations from ALOS SBAS InSAR

603 processing of (a) 2009.12.02, (b) 2010.01.17, (c) 2010.06.04, and (d) 2011.03.07.

604 Figure 7. Linear vertical deformation rate (cm/yr) estimated from (a) ERS/ENVISAT 
605 and (b) ALOS SBAS processing. The red-colored region represents ground subsidence

606 due to groundwater extraction. The contour means the iso-lines of groundwater level

607 changes measured in wells.

608 Figure 8. 10-year interval groundwater level changes measured at wells of (a)

$6091980 \mathrm{~s} \sim 1990 \mathrm{~s}$, (b) 1990s 2000s, and (c) 2000s 2010s, and 30-year water level changes

610 of (d) 1980s 2010s. The red and blue colored dots mean the increase and decrease of

611 water level at wells.

612 Figure 9. (a) Land subsidence monitoring and extensometer stations installed in Tucson,

613 and (b) Ellipsoid height changes measured in monitoring stations from 1998 to 2005;

614 red and blue arrows represent subsidence and uplift at the sites, and the length of arrows

615 expresses the amount of the ellipsoid height change. Green arrows represent the change

616 of compactions, which were measured in the extensometers from October, 2005 to

617 September, 2012.

618 Figure 10. Monthly compaction (blue dots) from October, 2005 to September 2012, and

619 subsidence (red circles) estimated from ERS/ENVISAT and ALOS SBAS processing at

620 monitoring stations of (a) WR53, (b) X419, (c) XAVIER, and (d) 23CBA.

621 Figure 11. Vertical displacements from ERS/ENVISAT (black squares) and ALOS (red

622 dots) SBAS processing, and GPS ellipsoid height change (blue diamonds) from 1999 to 
6232005 at stations of (a) B7A, (b) WR56A, (c) WR142, (d) X419, (e) C45, (f)

624 MAGNETIC, (g) WR53, and (h) WR52.

625 Figure 12. Time-series vertical deformation (red circles and lines) from ERS/ENVISAT

626 SBAS processing and groundwater elevation (blue dots and lines) measured in WR56A

627 and WR52.

628 Figure 13. (a) Contour in a plain view of ERS/ENVISAT SBAS InSAR-derived vertical

629 deformation during 17-year span (A, B, C, D, and E regions are mostly affected by

630 ground subsidence), and 3-year interval ERS/ENVISAT SBAS InSAR-derived vertical

631 deformation of (b) 1993.11.09 1996.11.22, (c) 1996.11.22 1999. 11.12, (d)

632 1999.11.12 2002.04.05, (e) 2002.04.05 2004.12.10, (f) 2004.12.10 2007.10.26,

633 and (g) 2007.10.26 2010.09.10.

634 Figure 14. 3-year interval vertical displacements along the profiles of (a) a-a', (b) b-b',

635 (c) c-c', and (d) d-d' in Fig.13(c).

636

\section{Table Captions}

638 Table 1. SAR images used for ERS, ENVISAT, and ALOS SBAS processing 


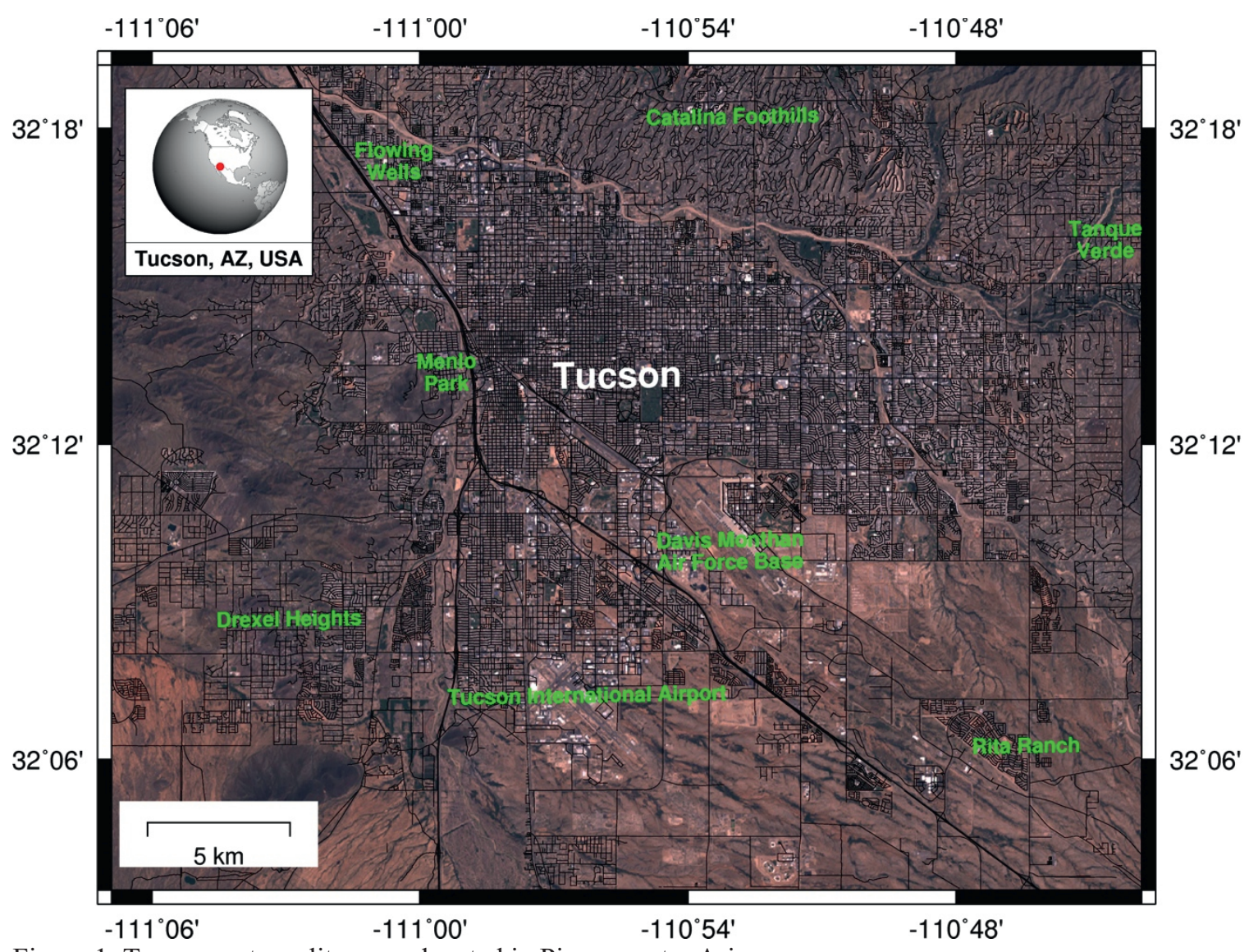

Figure(s)
Figure 1. Tucson metropolitan area located in Pima county, Arizona.

\section{'}

(1)




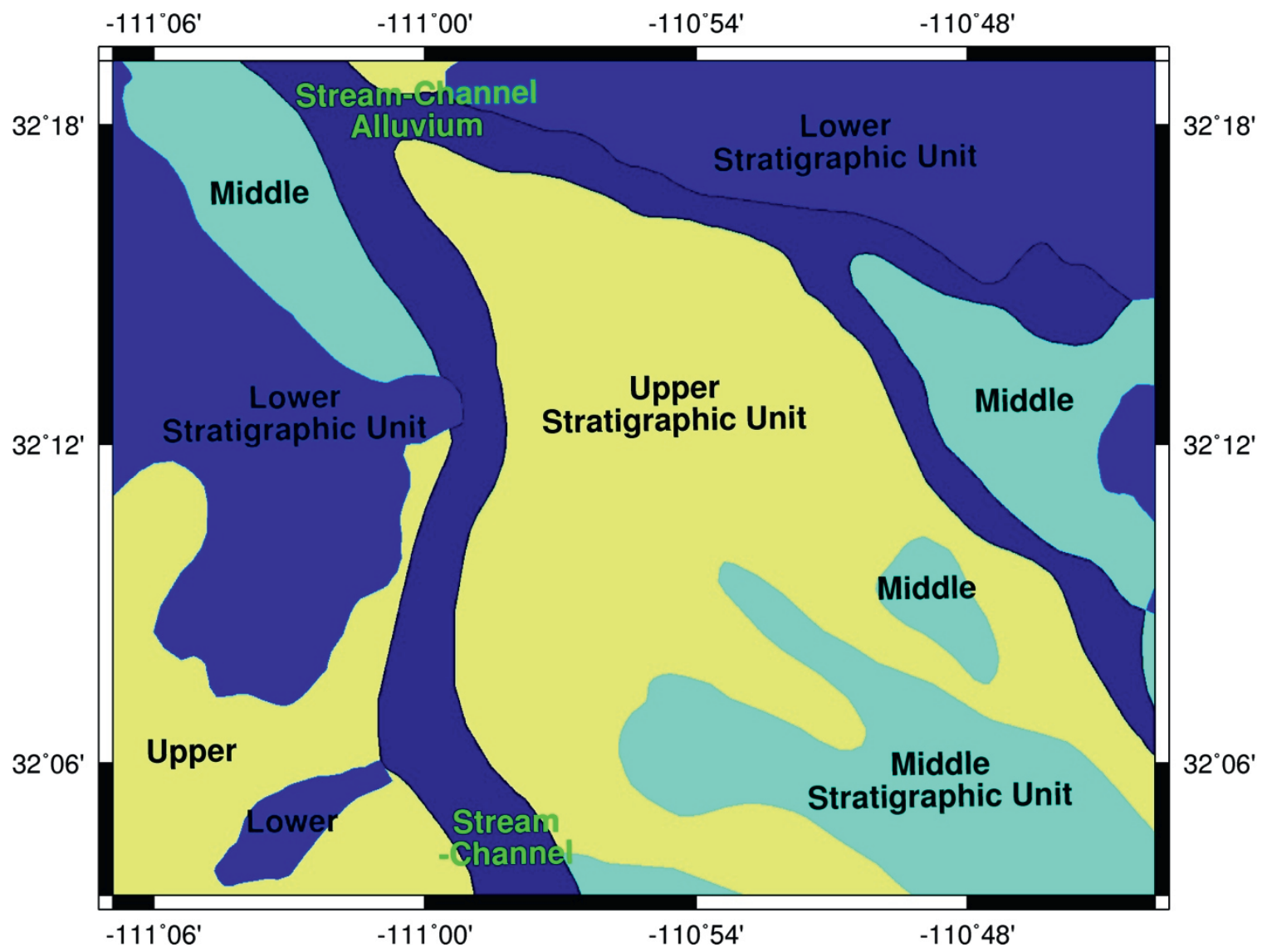

Figure 2. Generalized geological map in Tucson metropolitan area. The geological composition consists of upper, middle, and lower stratigraphic units. The area with upper stratigraphic unit is subject to ground deformation. 

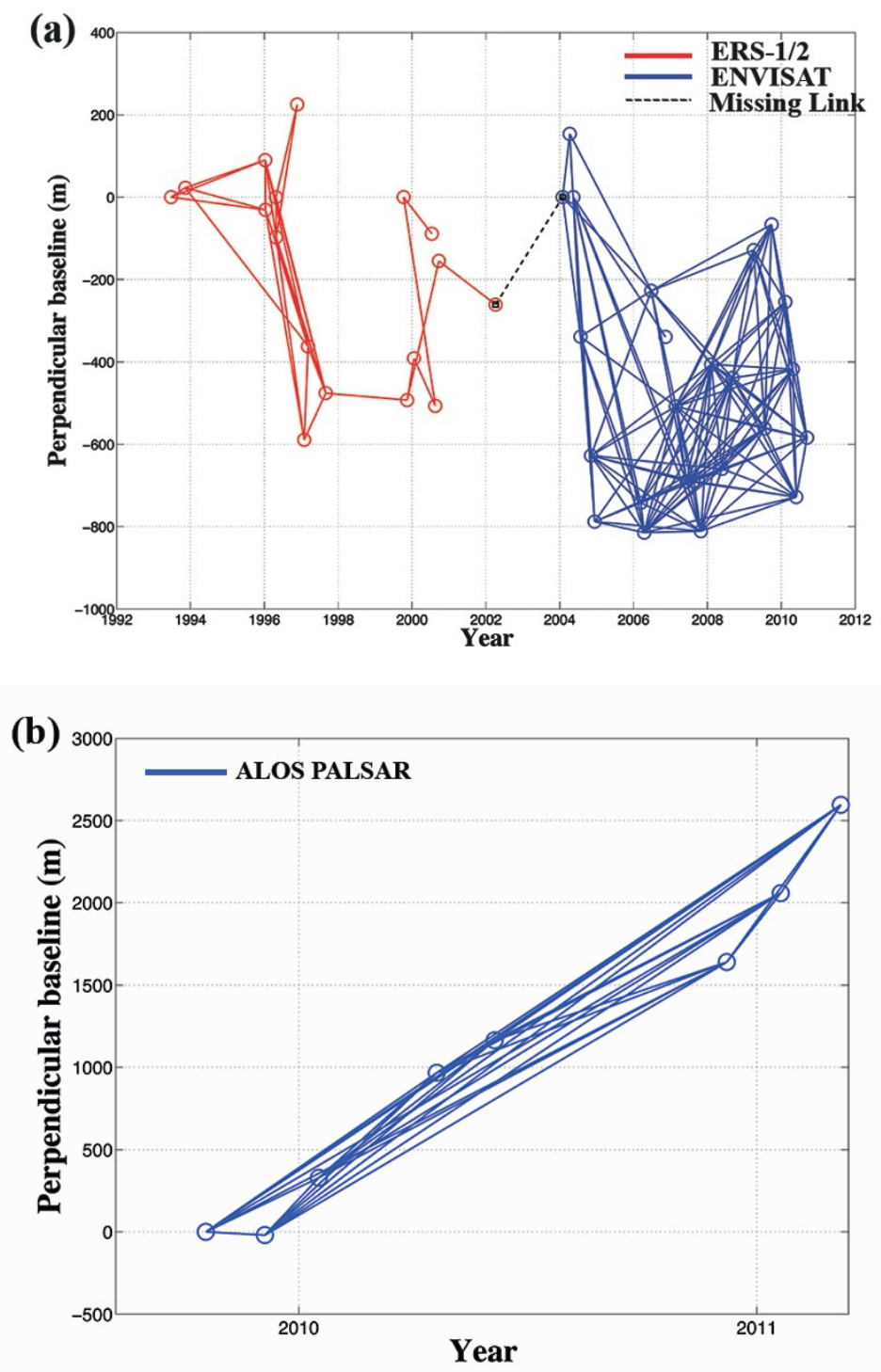

Figure 3. Diagram of perpendicular and temporal baseline of InSAR pairs ((a) ERS and ENVISAT InSAR pairs; red circles and lines are 29 ERS pairs, and blue circles and lines are 134 ENVISAT pairs. And, dashed black line represents simulated temporary InSAR pair to fill up data gap. (b) ALOS PALSAR InSAR pairs). 

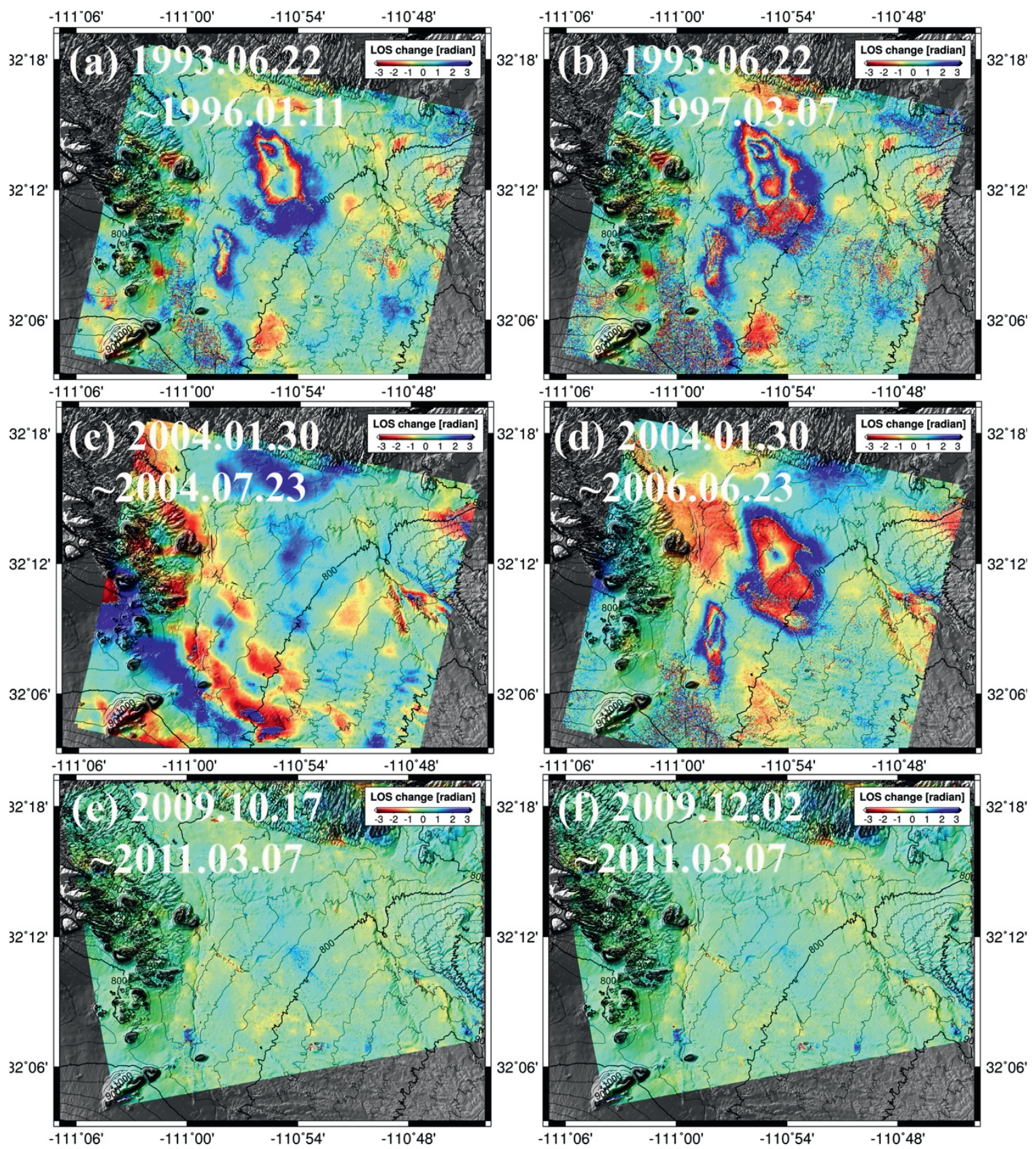

Figure 4. ERS-1/2 differential interferogram ((a) 1993.06.22 199601.11, (b) 1993.06.22 1997.03.07), ENVISAT differential interferogram ((c) 2004.01.30 2004.07.23, (d) 2004.01.30.2006.06.23), ALOS

PALSAR differential interferogram ((e) 2009.10.17 2011.03.07, (f) 2009.12.02 2011.03.07). 

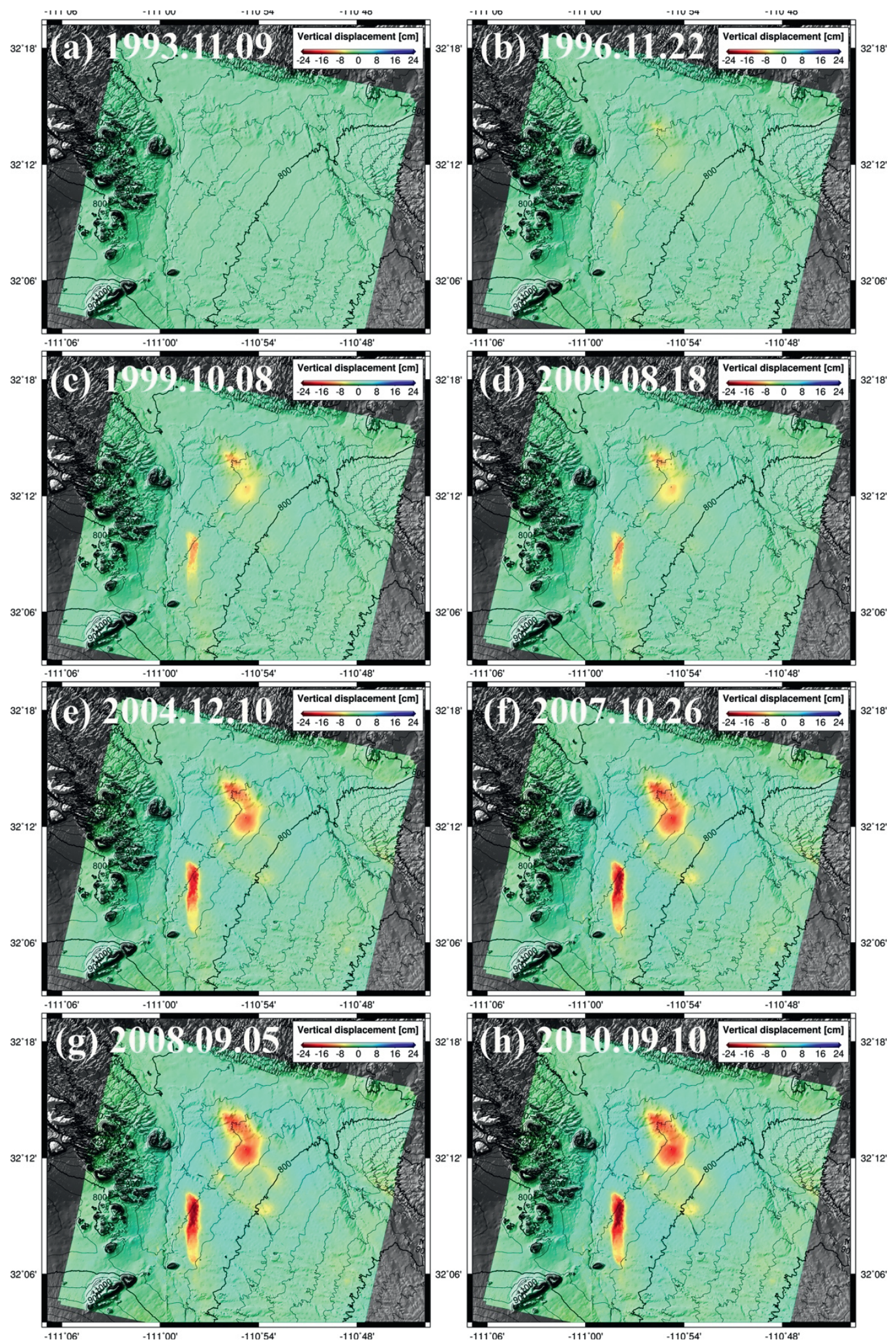

Figure 5. Time-series of (accumulated) vertical deformations from ERS/ENVISAT SBAS InSAR processing of (a) 1993.11.09, (b) 1996.11.22, (c) 1999.10.08, (d) 2000.08.18, (e) 2004.12.10, (f) 2007.10.26, and (g) 2008.09.05, and (h) 2010.09.10. 

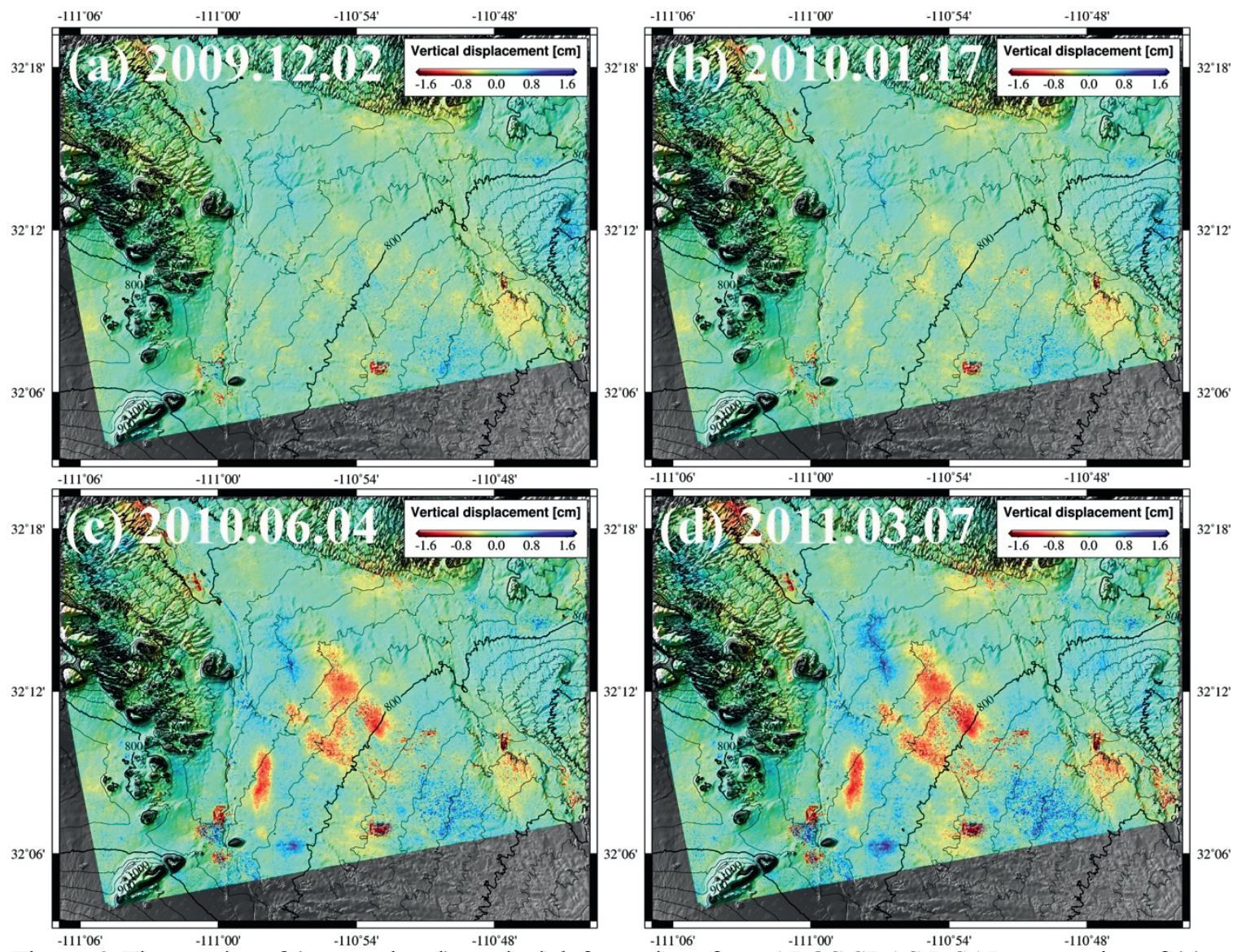

Figure 6. Time-series of (accumulated) vertical deformations from ALOS SBAS InSAR processing of (a) 2009.12.02, (b) 2010.01.17, (c) 2010.06.04, and (d) 2011.03.07. 

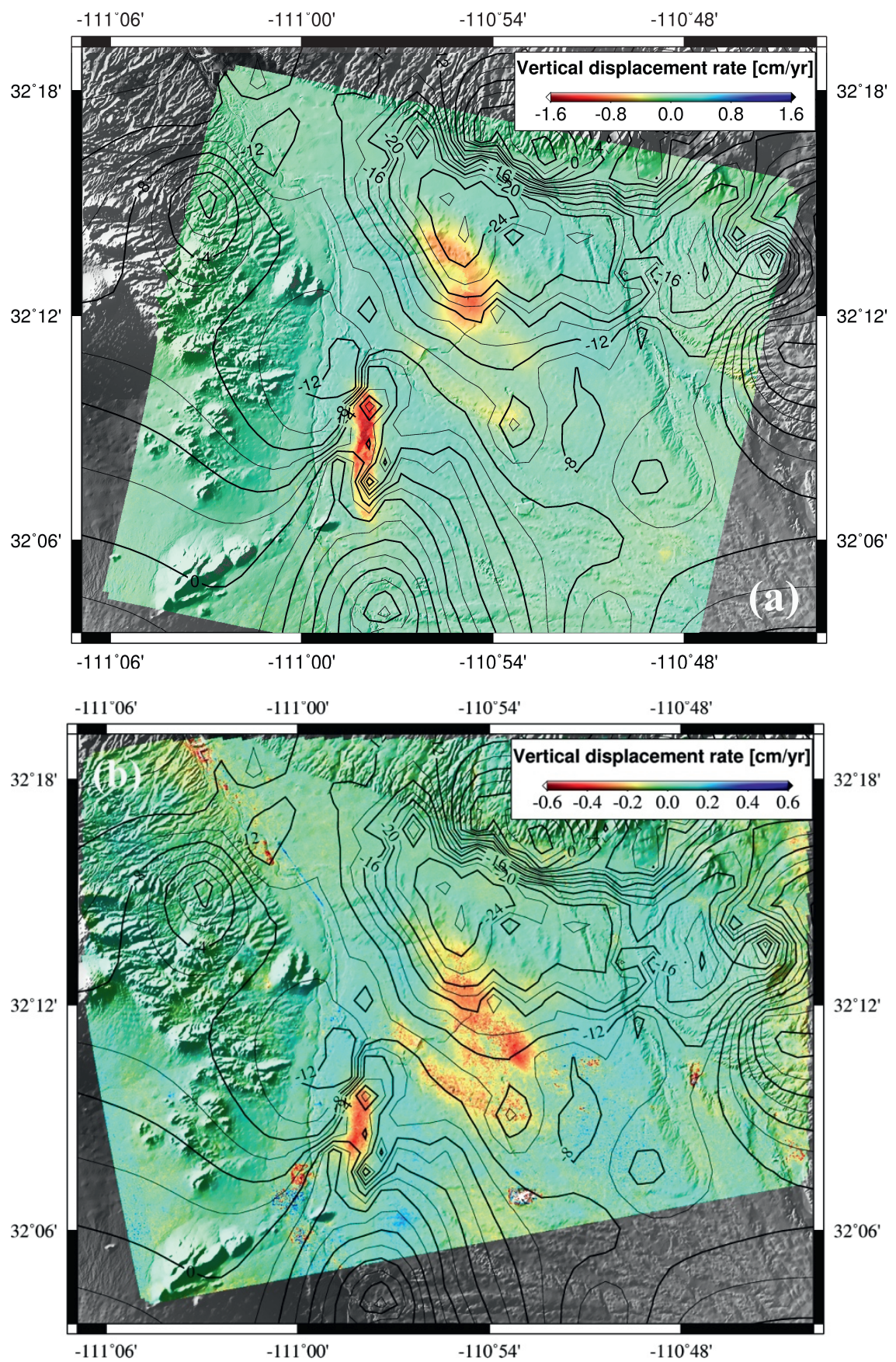

Figure 7. Linear vertical deformation rate (cm/yr) estimated from (a) ERS/ENVISAT and (b) ALOS SBAS processing. The red-colored region represents ground subsidence due to groundwater extraction. The contour means the iso-lines of groundwater level changes measured in wells. 

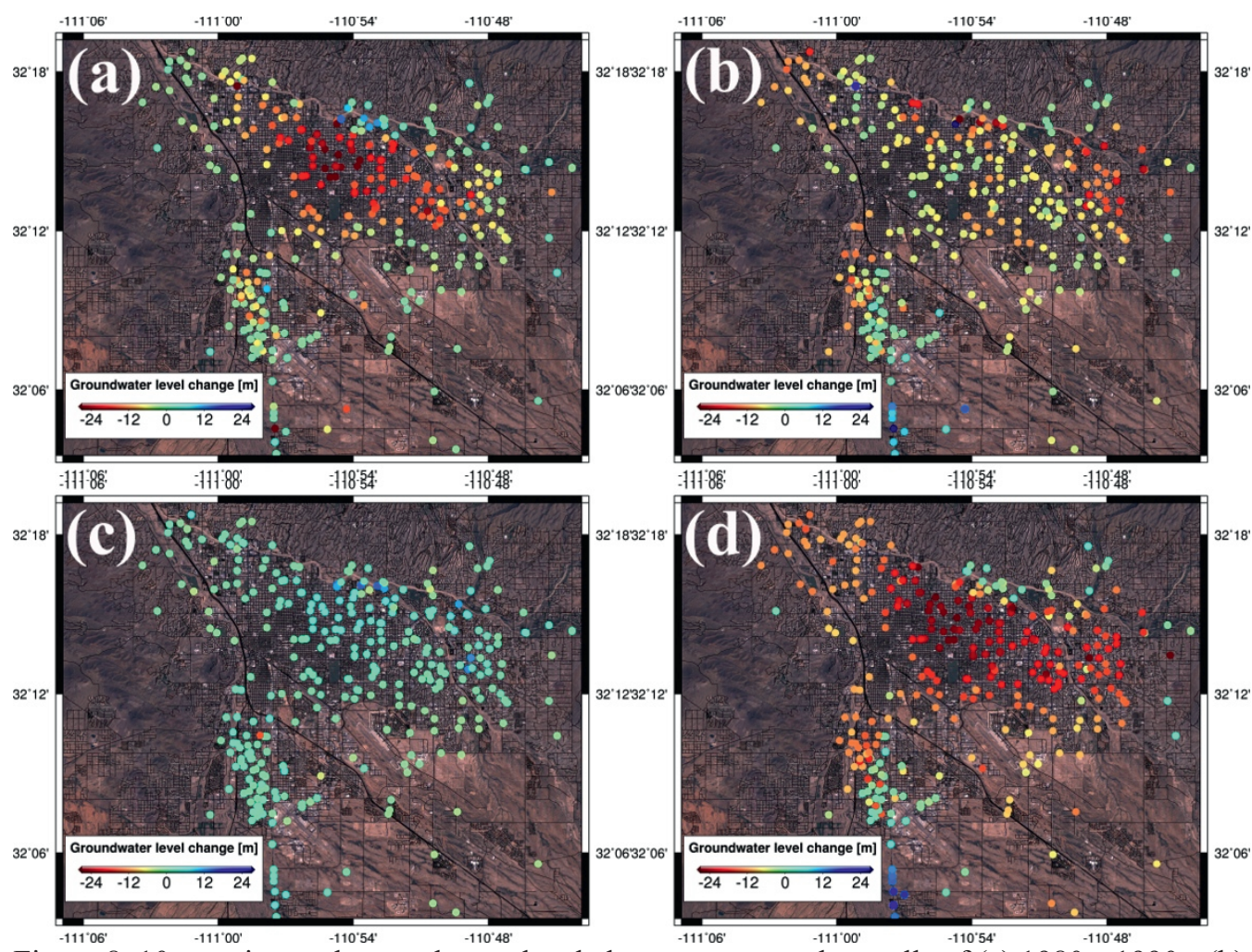

Figure 8. 10-year interval groundwater level changes measured at wells of (a) 1980s 1990s, (b) 1990s 2000s, and (c) 2000s 2010s, and 30-year water level changes of (d) 1980s 2010s. The red and blue colored dots mean the increase and decrease of water level at wells. 

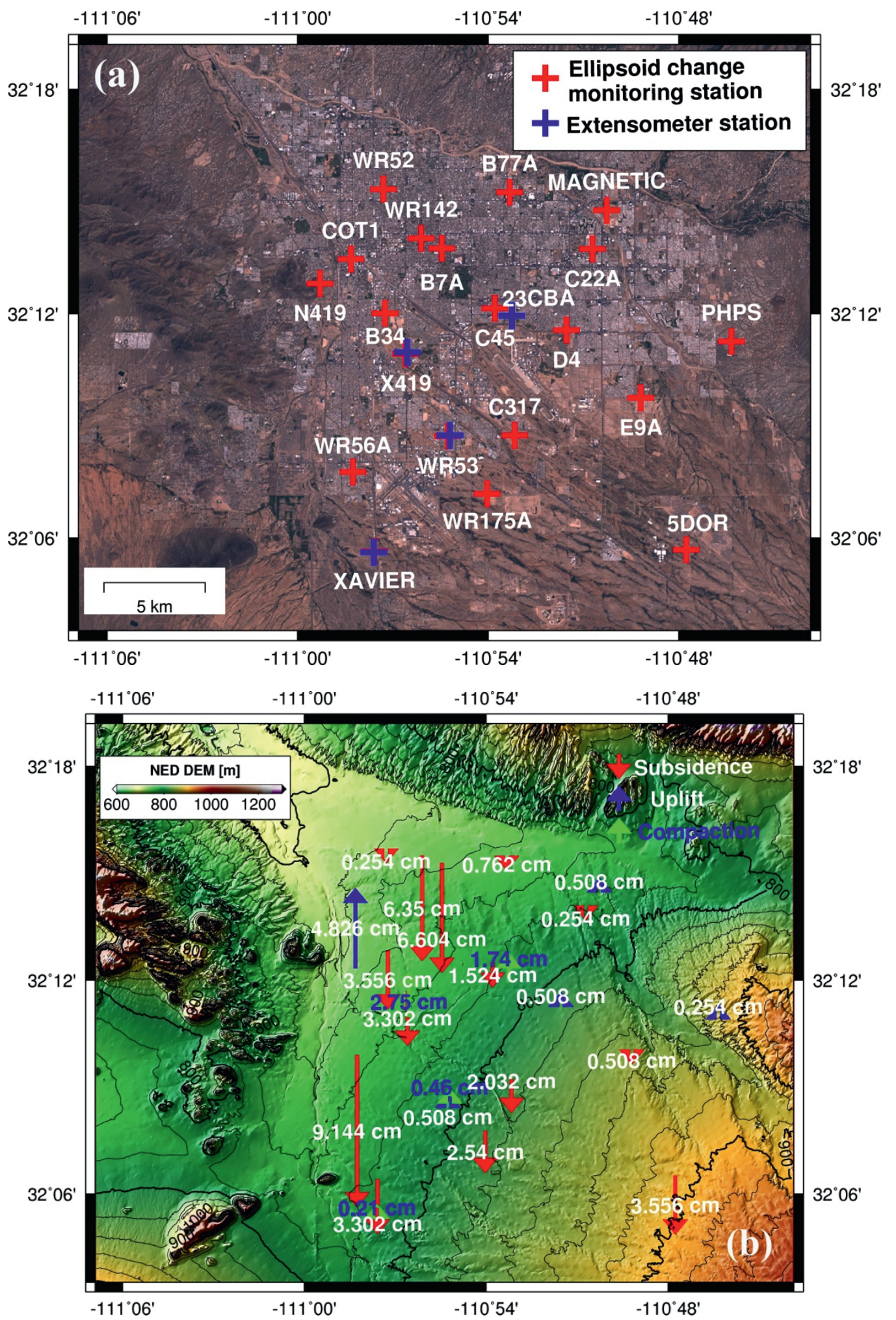

Figure 9. (a) Land subsidence monitoring and extensometer stations installed in Tucson, and (b) Ellipsoid height changes measured in monitoring stations from 1998 to 2005; red and blue arrows represent subsidence and uplift at the sites, and the length of arrows expresses the amount of the ellipsoid height change. Green arrows represent the change of compactions, which were measured in the extensometers from October, 2005 to September, 2012. 

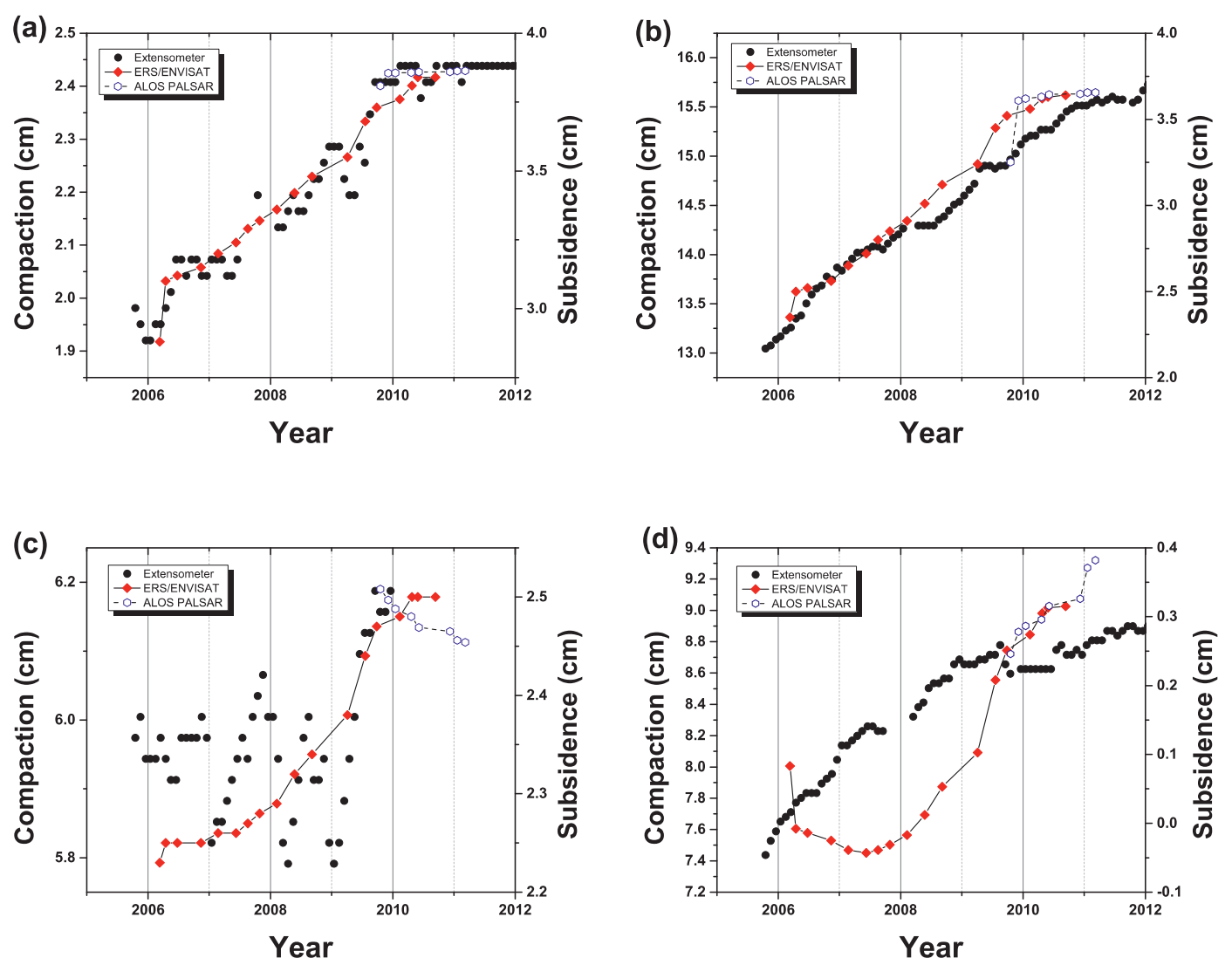

Figure 10. Monthly compaction (blue dots) from October, 2005 to September 2012, and subsidence (red circles) estimated from ERS/ENVISAT and ALOS SBAS processing at monitoring stations of (a) WR53, (b) X419, (c) XAVIER, and (d) 23CBA. 

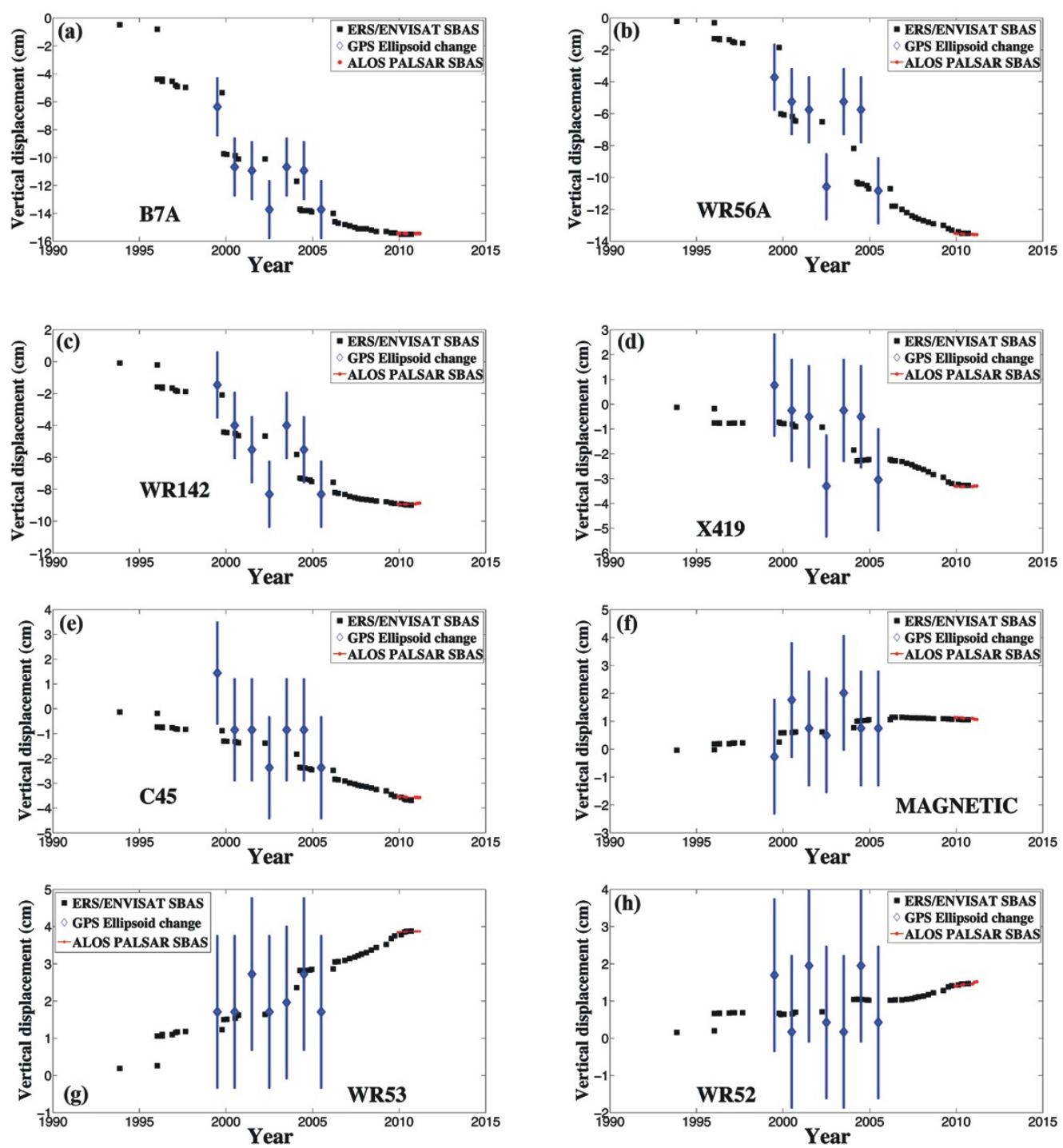

Figure 11. Vertical displacements from ERS/ENVISAT (black squares) and ALOS (red dots) SBAS processing, and GPS ellipsoid height change (blue diamonds) from 1999 to 2005 at stations of (a) B7A, (b) WR56A, (c) WR142, (d) X419, (e) C45, (f) MAGNETIC, (g) WR53, and (h) WR52. 


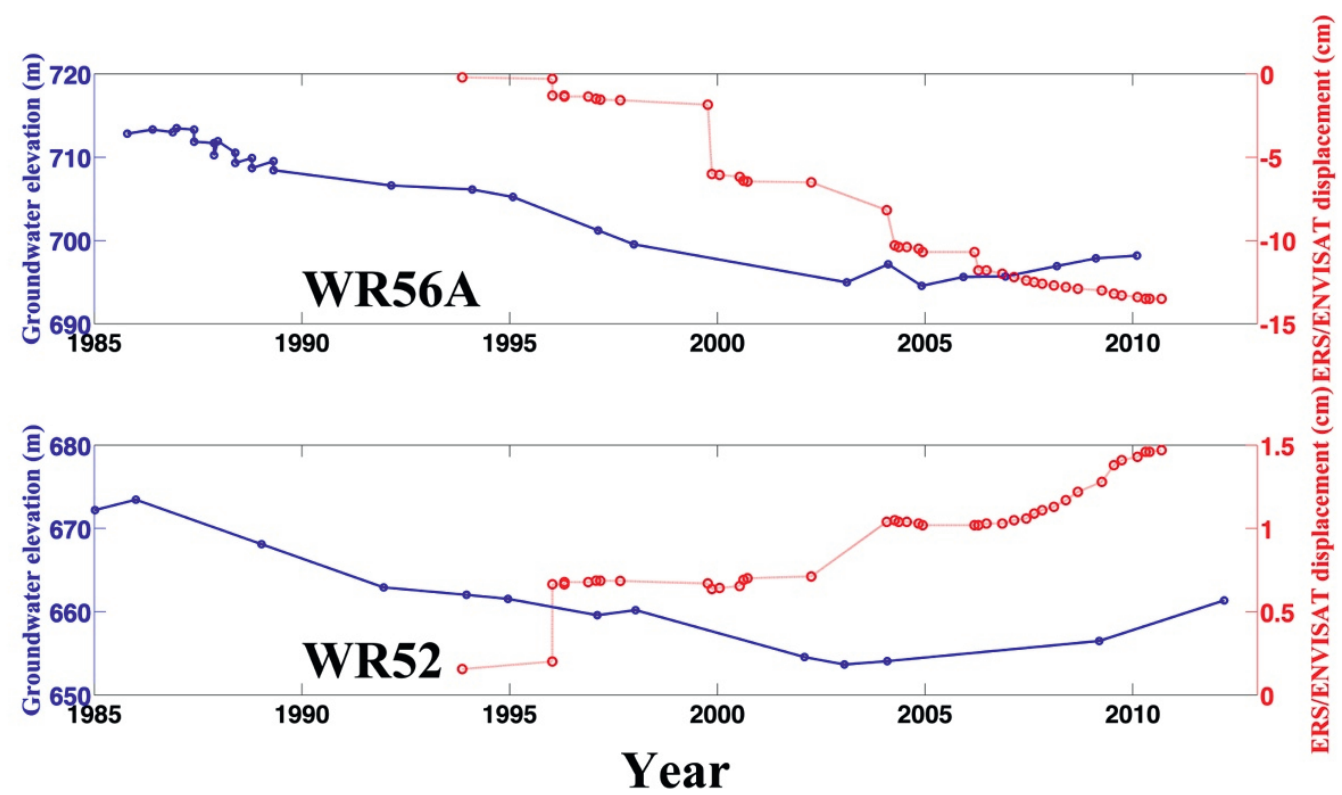

Figure 12. Time-series vertical deformation (red circles and lines) from ERS/ENVISAT SBAS processing and groundwater elevation (blue dots and lines) measured in WR56A and WR52. 

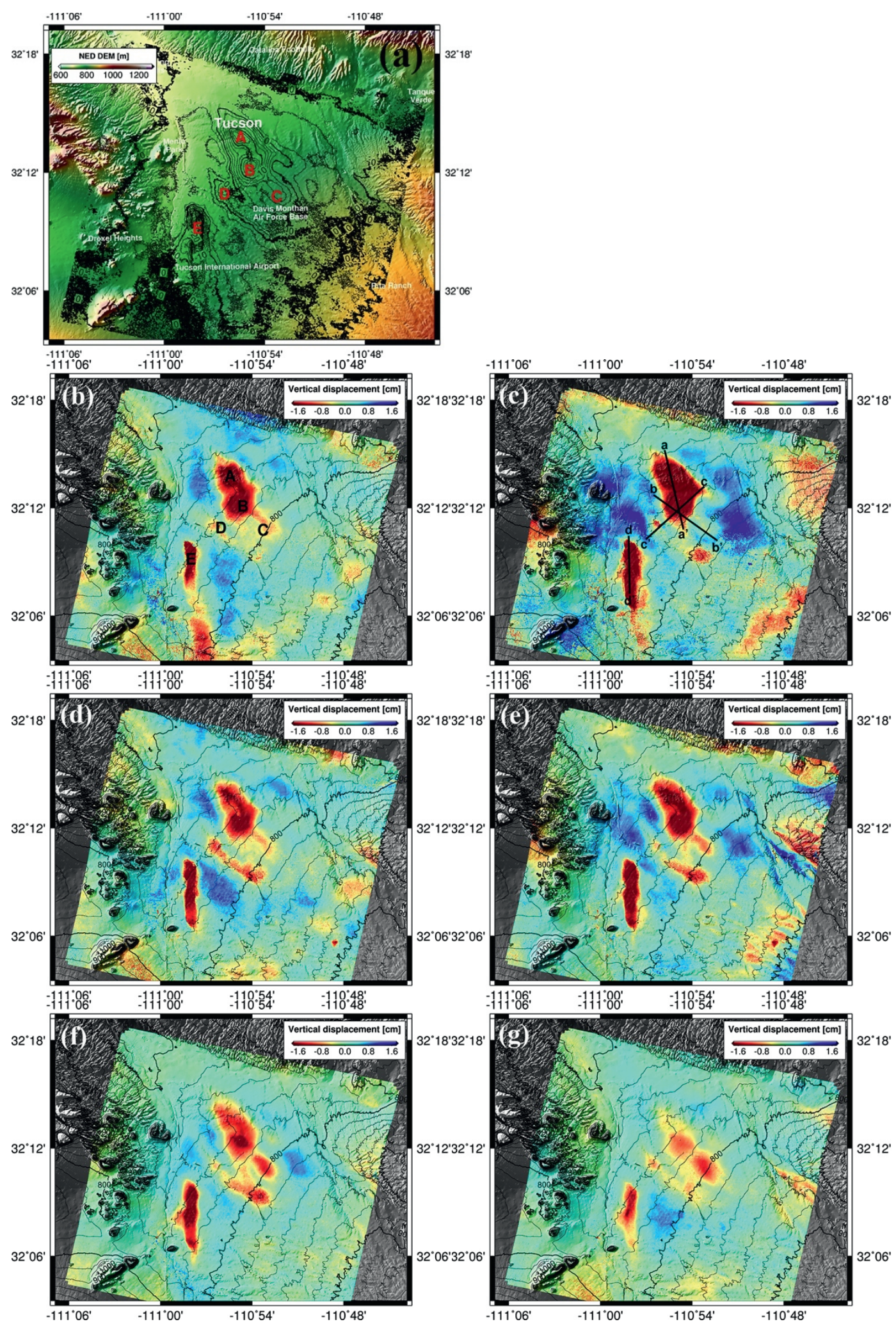

Figure 13. (a) Contour in a plain view of ERS/ENVISAT SBAS InSAR-derived vertical deformation during 17-year span (A, B, C, D, and E regions are mostly affected by ground subsidence), and 3-year interval ERS/ENVISAT SBAS InSAR-derived vertical deformation of (b) 1993.11.09 1996.11.22, (c) 1996.11.22 1999. 11.12, (d) 1999.11.12 2002.04.05, (e) 2002.04.05 2004.12.10, (f) 2004.12.10 2007.10.26, and (g) 2007.10.26 2010.09.10. 

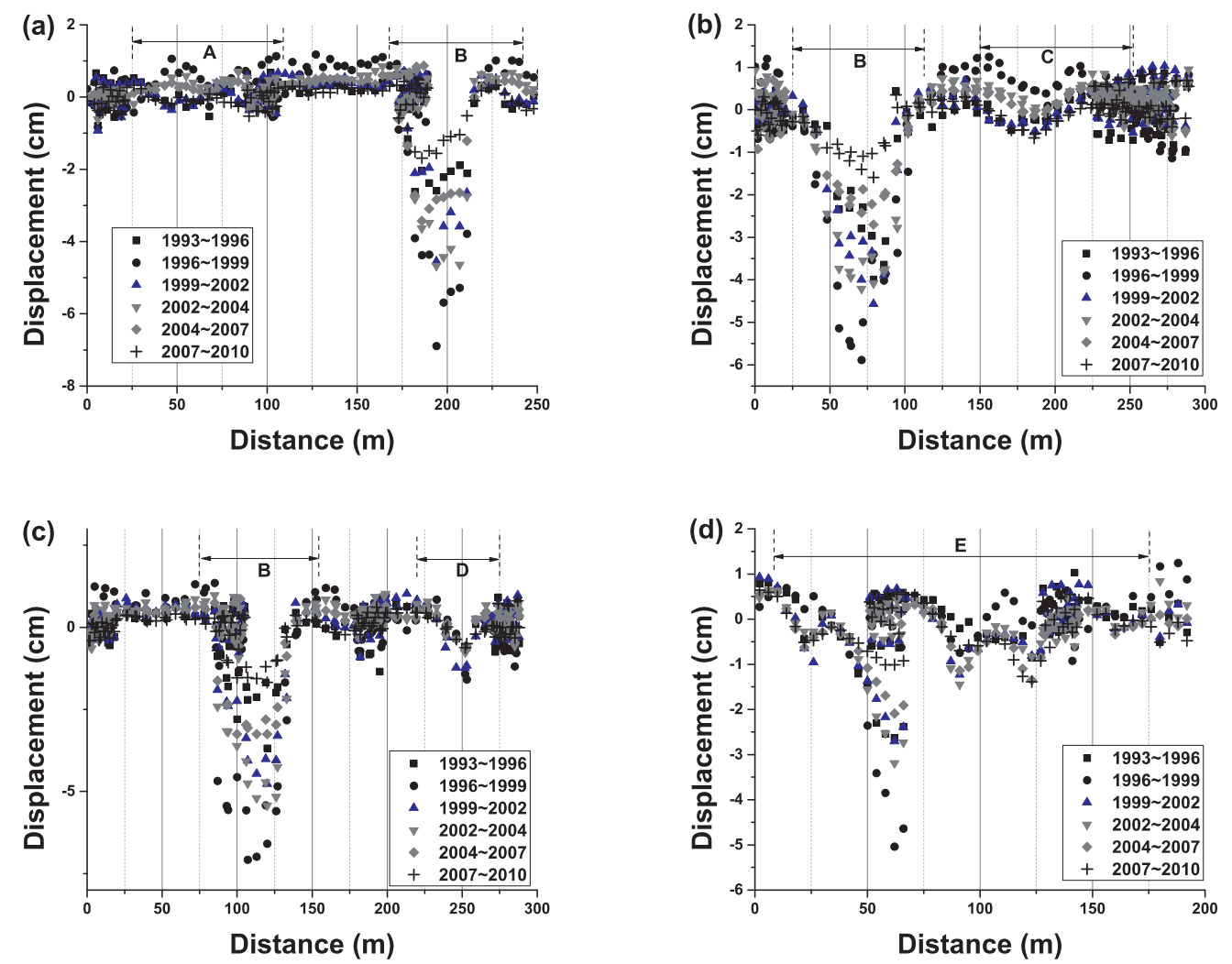

Figure 14. 3-year interval vertical displacements along the profiles of (a) a-a', (b) b-b', (c) c-c', and (d) d-d' in Fig.13(c). 
Table 1. SAR images used for ERS, ENVISAT, and ALOS SBAS processing

\begin{tabular}{|c|c|c|c|c|c|c|c|c|c|}
\hline Mission & Date & Path & Direction & $\begin{array}{l}\text { Incidence } \\
\text { Angle }\left(^{\circ}\right)\end{array}$ & Mission & Date & Path & Direction & $\begin{array}{l}\text { Incidence } \\
\text { Angle }\left(^{\circ}\right)\end{array}$ \\
\hline ERS & 19930622 & 456 & Descending & 23.2711 & ENVISAT & 20060623 & 456 & Descending & 22.7884 \\
\hline ERS & 19931109 & 456 & Descending & 23.2711 & ENVISAT & 20061110 & 456 & Descending & 22.7884 \\
\hline ERS & 19960111 & 456 & Descending & 23.2711 & ENVISAT & 20070223 & 456 & Descending & 22.7884 \\
\hline ERS & 19960112 & 456 & Descending & 23.2711 & ENVISAT & 20070608 & 456 & Descending & 22.7884 \\
\hline ERS & 19960425 & 456 & Descending & 23.2711 & ENVISAT & 20070817 & 456 & Descending & 22.7884 \\
\hline ERS & 19960426 & 456 & Descending & 23.2711 & ENVISAT & 20071026 & 456 & Descending & 22.7884 \\
\hline ERS & 19961122 & 456 & Descending & 23.2711 & ENVISAT & 20080208 & 456 & Descending & 22.7884 \\
\hline ERS & 19970131 & 456 & Descending & 23.2711 & ENVISAT & 20080523 & 456 & Descending & 22.7884 \\
\hline ERS & 19970307 & 456 & Descending & 23.2711 & ENVISAT & 20080905 & 456 & Descending & 22.7884 \\
\hline ERS & 19970829 & 456 & Descending & 23.2711 & ENVISAT & 20090403 & 456 & Descending & 22.7884 \\
\hline ERS & 19991008 & 456 & Descending & 23.2711 & ENVISAT & 20090717 & 456 & Descending & 22.7884 \\
\hline ERS & 19991112 & 456 & Descending & 23.2711 & ENVISAT & 20090925 & 456 & Descending & 22.7884 \\
\hline ERS & 20000121 & 456 & Descending & 23.2711 & ENVISAT & 20100212 & 456 & Descending & 22.7884 \\
\hline ERS & 20000714 & 456 & Descending & 23.2711 & ENVISAT & 20100423 & 456 & Descending & 22.7884 \\
\hline ERS & 20000818 & 456 & Descending & 23.2711 & ENVISAT & 20100528 & 456 & Descending & 22.7884 \\
\hline ERS & 20000922 & 456 & Descending & 23.2711 & ENVISAT & 20100910 & 456 & Descending & 22.7884 \\
\hline ERS & 20020405 & 456 & Descending & 23.2711 & ALOS & 20091017 & 203 & Ascending & 38.7249 \\
\hline ENVISAT & 20040130 & 456 & Descending & 22.7884 & ALOS & 20091202 & 203 & Ascending & 38.7249 \\
\hline ENVISAT & 20040409 & 456 & Descending & 22.7884 & ALOS & 20100117 & 203 & Ascending & 38.7249 \\
\hline ENVISAT & 20040514 & 456 & Descending & 22.7884 & ALOS & 20100419 & 203 & Ascending & 38.7249 \\
\hline ENVISAT & 20040723 & 456 & Descending & 22.7884 & ALOS & 20100604 & 203 & Ascending & 38.7249 \\
\hline ENVISAT & 20041105 & 456 & Descending & 22.7884 & ALOS & 20101205 & 203 & Ascending & 38.7249 \\
\hline ENVISAT & 20041210 & 456 & Descending & 22.7884 & ALOS & 20110120 & 203 & Ascending & 38.7249 \\
\hline ENVISAT & 20060310 & 456 & Descending & 22.7884 & ALOS & 20110307 & 203 & Ascending & 38.7249 \\
\hline ENVISAT & 20060414 & 456 & Descending & 22.7884 & & & & & \\
\hline
\end{tabular}

